\title{
Slowing down the deactivation of H-ZSM-5 zeolite catalyst in the methanol-to-olefin (MTO) reaction by $P$ or $Z n$ modifications
}

José Valecillos $^{1}$, Eva Epelde ${ }^{1}$, Jonathan Albo $^{2}$, Andrés T. Aguayo ${ }^{1}$, Javier Bilbao ${ }^{1}$, and Pedro Castaño ${ }^{1,3^{*}}$

1 Department of Chemical Engineering, University of the Basque Country (UPV/EHU), P.O. Box 644, E48080, Bilbao, Spain; pedro.castano@ehu.eus

2 Department of Chemical \& Biomolecular Engineering, University of Cantabria, Avda. Los Castros s/n, 39005 Santander, Spain.

3 Multiscale Reaction Engineering, KAUST Catalysis Center (KCC), King Abdullah University of Science and Technology (KAUST), Thuwal, 23955-6900, Saudi Arabia; pedro.castano@kaust.edu.sa

\begin{abstract}
The benefits of H-ZSM-5 zeolite modification with $\mathrm{H}_{3} \mathrm{PO}_{4}$ or $\mathrm{ZnCl}_{2}$ have been analyzed during the methanol to olefins (MTO) reaction. The catalysts were prepared, characterized and tested using three different reactors: fixed-bed, operando FTIR and UVvis. The spent catalysts were further characterized for analyzing the nature and location of the species trapped. The results show that the zeolite modified with $\mathrm{H}_{3} \mathrm{PO}_{4}$ has suffered a simultaneous dealumination, leading to a decrease of number of acid sites and activity. However, the zeolite modified with $\mathrm{ZnCl}_{2}$ shows the inclusion of $\mathrm{Zn}$ transforming Brønsted into Lewis acid sites, leading to reaction intermediates (hydrocarbon pool species) that decreases the rate of reaction but improves propylene selectivity $(+10 \%)$, slows downs coke formation $(-42 \%)$ and expands catalytic lifetime $(+80 \%)$. The distinct effect of $\mathrm{Zn}$ modification, typically associated with the promotion of aromatics, is explained on the grounds of the severe transformation of the strong and Brønsted acid sites.
\end{abstract}

Keywords: methanol-to-olefins; $\mathrm{H}-\mathrm{ZSM}-5$ zeolite; $\mathrm{H}_{3} \mathrm{PO}_{4}$ and $\mathrm{ZnCl}_{2}$ modification; catalyst deactivation; fixed-bed reactor; FTIR and UV-vis operando reactors. 


\section{INTRODUCTION}

Methanol is a promising non-petroleum platform chemical to obtain many highly demanded petrochemical products or fuels. One remarkable process is the methanol conversion into hydrocarbons (MTH), which is a very versatile process to yield gasoline (MTG), light olefins (MTO) or aromatics (MTA). The MTG process was developed during the petroleum crisis in early 1970s and implemented as an alternative production path from coal or natural gas to gasoline [1,2]. The MTH process alternatives have raised renewed interests due to the possible use of renewable resources such as biomass [3] or $\mathrm{CO}_{2}$ [4]. The current state-of-the-art has been summarized in critical reviews such as these focused on catalysts [5], reaction mechanisms [6-9], deactivation [10,11] and industrial implementation in China of the MTO process [12].

Light olefins, namely ethylene, propylene and butenes, are among the most important building blocks of the petrochemical industry and the MTO process is a sustainable route for their production. The challenges of the MTO process is attaining high light olefins selectivity and prolonging the catalyst lifetime. In this sense, the SAPO-34 silicoaluminophosphate catalyst is particularly selective to light olefins but it has a very short catalyst lifetime [5,12]. The H-ZSM-5 zeolite catalyst can keep the activity for much longer but it has a poorer light olefins selectivity [13]. In this sense, a major drive for MTO research is precisely modifying the properties of H-ZSM-5 zeolite for increasing light olefins selectivity.

The current view of the MTO reaction network considers the dehydration of methanol into dimethyl ether and water, and the conversion of oxygenates (methanol and dimethyl ether) into hydrocarbons in three dynamic steps [6,9,11,14,15]: (1) induction period, in which the $\mathrm{C}-$ Cbonds are formed from methoxy species, and generating the hydrocarbon pool species; (2) autocatalytic period, in which the adsorbed or trapped hydrocarbon pool species formed in the previous step act as catalytic sites for faster conversion of methanol and dimethyl ether; and (3) deactivation period, in which the always evolving hydrocarbon pool species condensate into deactivating coke species. It is commonly accepted that the hydrocarbon pool species react throughout a dual-cycle mechanism that involves olefins or aromatics, each in cycles of methylation-oligomerization and dealkylation-cracking. In parallel, additional cyclization, hydrogen transfer (also called hydride transfer) and condensation reactions of olefins and other molecules lead to a relatively complex product mixture. In general, the hydrocarbon pool species have a pivotal role as active intermediates and as coke precursors. The role as active/inactive of each species depends on its nature and location: polymethylbenzenes (polyMB) are active species in the aromatic cycle to form ethylene and propylene $[6,9,10,16-18]$, but its reactivity depends on the number of methyl substituents. Highly methylated benzene 
species, such as hexamethylbenzene (hexaMB), has lower activity than lower methylated ones. Besides, the former species tend to degrade into truly deactivating species in the zeolite catalysts $[9,11,19]$, or as polycyclic aromatics on the external surface of the zeolite [20,21]. An additional pathway of deactivation may occur in the first two steps of reaction, which is due to the formation of oxygenates. In this regard, two mechanisms have been proposed: (i) the methoxy groups react with carbon monoxide that comes from methanol decomposition forming formaldehyde [20,22-24], that subsequently react with acetyl species forming furans by cyclization reactions [20]; and (ii) the formation of methylated cyclopentenones that are actually intermediates in the aromatic coke formation [23].

Accounting the reaction network, the mainstream research related with the MTO reaction has focused on designing catalysts that specifically control the hydrocarbon pool species in order to control the selectivity and stability of the catalyst. One way of achieving this is to perform post-treatment of zeolites in order to tune their properties. A relevant case in the literature is the modification of $\mathrm{H}-\mathrm{ZSM}-5$ zeolite with $\left(\mathrm{NH}_{4}\right)_{3} \mathrm{PO}_{4}$ or $\mathrm{H}_{3} \mathrm{PO}_{4}$ that improves light olefins selectivity and stability as compared with parent H-ZSM-5 catalysts in the MTO reaction [25-30], and also in the interconversion of olefins [31]. Van der Bij and Weckhuysen [25] have published a review on P modified zeolite materials, in which they summarized that the acid site loss and changes in shape selectivity have an important effect on light olefins selectivity and catalyst stability in the MTO reaction. The acid site loss is due to the strong interaction of $\mathrm{P}$ with $\mathrm{Al}$, causing a dealumination of the zeolite framework. This is verified by the increase of extraframework (hexa-coordinated) $\mathrm{Al}$ at the expense of framework (tetra-coordinated) $\mathrm{Al}$ [25,32-34]. The shape selectivity changes are due to the modifications of the zeolite pore system, preventing diffusion and inhibiting the formation of voluminous species during the reaction [25].

Other relevant modification is the introduction of metal species in H-ZSM-5 zeolites. In this case, the Zn modified zeolites are commonly used as catalysts in the MTH reaction, and they are particularly selective to form aromatics (MTA reaction) [35-40]. This is due to a synergy between Brønsted acid sites (BAS) that catalyze most of the MTH reactions and $\mathrm{Zn}$ species that catalyze dehydrogenation reactions of olefins and naphthenes contributing to form aromatics $[36,38,41,42]$. Although all $\mathrm{Zn}$ modified zeolite catalysts are mostly intended for boosting aromatics production, we found some cases in the literature in which light olefins production can be favored over aromatics. Zhang et al. [43] focused on studying the performance of Zn modified H-ZSM-5 catalysts in the MTO reaction. They modified a H-ZSM-5 zeolite by impregnation with a $\mathrm{Zn}\left(\mathrm{NO}_{3}\right)_{2}$ solution and performed the MTO reaction at $520^{\circ} \mathrm{C}$. Under such reaction conditions, they obtained a product distribution dominated by carbon oxides (47.1\%) and light olefins $(40.1 \%)$ on 
the $\mathrm{Zn}$ modified catalyst whereas light olefins (45\%), methane $(24.6 \%)$ and $\mathrm{C}_{5^{+}}$ hydrocarbons (23.1\%) dominated on the parent H-ZSM-5 catalyst. Although their results suggest that the $\mathrm{Zn}$ modified catalyst promotes the methanol decomposition into carbon oxides, the light olefins selectivity is favored over other hydrocarbons (including aromatics) in comparison with the parent catalyst. Another important factor for their observations is the reaction conditions used (very high temperature, dilution of methanol with $40 \mathrm{wt} \%$ of water and very high space times), that may favor other reactions such the steam reforming of methanol. In another study focused on the MTA reaction at $480{ }^{\circ} \mathrm{C}$, Bi et al. [38] reported that the zinc precursor salts have an important effect on the aromatics selectivity. They showed that the use of $\mathrm{ZnSO}_{4}, \mathrm{Zn}(\mathrm{OAc})_{2}$ and $\mathrm{Zn}\left(\mathrm{NO}_{3}\right)_{2}$ undoubtedly improves the aromatics selectivity (ranging 61.5-77.9\%), whereas the use of $\mathrm{ZnCl}_{2}$ slightly reduces it down to $41.8 \%$ as compared with $46.9 \%$ for the corresponding parent H-ZSM-5 catalyst. Additionally, their results showed that the light olefins selectivity improves for all the $\mathrm{Zn}$ modified catalysts, ranging 9.2-22\% when using $\mathrm{ZnSO}_{4}, \mathrm{Zn}(\mathrm{OAc})_{2}$ and $\mathrm{Zn}\left(\mathrm{NO}_{3}\right)_{2}$, and increasing up to $37.9 \%$ for $\mathrm{ZnCl}_{2}$ compared with $7.4 \%$ for the corresponding parent H-ZSM-5 catalyst. Based on all the above, two important parameters play a role to favor or disfavor aromatic selectivity: (1) the $\mathrm{Zn}$ precursor salt and (2) the reaction conditions. The work of Zhang et al. clearly demonstrated that $\mathrm{ZnCl}_{2}$ modification favors the selectivity of light olefins over aromatics. On the other hand, a higher space time favors the interconversion of the light olefins into aromatics. The temperature is also critical for favoring desired reactions and preventing secondary ones. Thus, $\mathrm{ZnCl}_{2}$ modified $\mathrm{H}-\mathrm{ZSM}-5$ zeolite is a prospective catalyst for the MTO reaction under appropriate reaction conditions. Moreover, Zn modification cause a decrease of BAS and an increase of Lewis acid sites (LAS) $[35,36,43]$. This would lead to a drop in the catalytic activity but an improvement of catalyst stability and light olefin selectivity, as other authors have systematically proved for $\mathrm{Mg}, \mathrm{B}$, or Ca modified zeolites [44,45].

These evidences show the potential improvements of the MTO reaction performance by selectively modifying H-ZSM-5 zeolites, particularly by tuning the dual-cycle mechanism in favor of the olefinic cycle $[46,47]$. Therefore, we focus our work on comparing two prospective modifiers, $\mathrm{H}_{3} \mathrm{PO}_{4}$ and $\mathrm{ZnCl}_{2}$, of the $\mathrm{H}-\mathrm{ZSM}-5$ zeolite catalyst in the MTO reaction. Our aim is to bring a better insight on the power of a specific modifier to boost light olefins formation, highlighting their impact on the deactivation and the relationship between the mechanisms of light olefins formation and coke formation. For this, we performed the MTO reaction in a fixed-bed reactor and operando reactors in which we can follow the evolution of reaction intermediates. The latter experiments are based on Fourier-transform infrared (FTIR) and ultraviolet-visible (UVvis) spectroscopies, and they are intended to gain a better insight on how phosphorus or 
zinc affects the MTO reaction in the unsteady state, more precisely the formation of hydrocarbon pool species, and ultimately into catalyst deactivation. Furthermore, we highlight the $\mathrm{Zn}$ modification of H-ZSM-5 zeolites as a prospective catalyst for the MTO reaction considering its advantages over selectivity and deactivation.

\section{EXPERIMENTAL}

\subsection{Zeolite and catalyst preparation}

We prepared two modified zeolites from a parent ZSM-5 zeolite (Zeolyst International, nominal molar $\mathrm{Si} / \mathrm{Al}$ ratio $=40$ ) using $\mathrm{H}_{3} \mathrm{PO}_{4}$ or $\mathrm{ZnCl}_{2}$. First, the parent zeolite was subjected to calcination (as it was obtained in the ammonium form) following the next steps: (1) heating from $25{ }^{\circ} \mathrm{C}$ to $400{ }^{\circ} \mathrm{C}$ at $5{ }^{\circ} \mathrm{C} \mathrm{min}-1$; (2) holding isothermal at $400{ }^{\circ} \mathrm{C}$ for $3 \mathrm{~h}$; (3) heating from $400{ }^{\circ} \mathrm{C}$ to $450{ }^{\circ} \mathrm{C}$ at $3.3{ }^{\circ} \mathrm{C} \mathrm{min}^{-1}$; (4) holding isothermal at 450 ${ }^{\circ} \mathrm{C}$ for $16 \mathrm{~h}$; (5) heating from $450{ }^{\circ} \mathrm{C}$ to $550{ }^{\circ} \mathrm{C}$ at $3.3{ }^{\circ} \mathrm{C} \mathrm{min}^{-1}$; (6) holding isothermal at $550{ }^{\circ} \mathrm{C}$ for $3 \mathrm{~h}$; and (7) cooling down to $25{ }^{\circ} \mathrm{C}$ at $4.4{ }^{\circ} \mathrm{C} \mathrm{min}-1$. The zeolites were named as HZ5, parent H-ZSM-5 zeolite; PZ5, P-modified zeolite; and ZnZ5, Zn-modified zeolite. The PZ5 zeolite was prepared by impregnating $10 \mathrm{~g}$ of $\mathrm{HZ} 5$ zeolite with a $\mathrm{H}_{3} \mathrm{PO}_{4}$ solution to theoretically give $1 \mathrm{wt} \%$ of $\mathrm{P}$. The impregnation was carried out in a rotatory evaporator under vacuum at $60{ }^{\circ} \mathrm{C}$, and then the impregnated zeolite powder was dried at $110{ }^{\circ} \mathrm{C}$ for $12 \mathrm{~h}$. The ZnZ5 zeolite was prepared by ion exchanging $10 \mathrm{~g}$ of ammonium $\mathrm{ZSM}-5$ zeolite with a $\mathrm{ZnCl}_{2}$ solution in a stirred flask at $60{ }^{\circ} \mathrm{C}$ for $24 \mathrm{~h}$. The resulting ionexchanged zeolite powder was washed with distillate water, filtered, dried at room temperature for $24 \mathrm{~h}$ and at $110^{\circ} \mathrm{C}$ for $12 \mathrm{~h}$. The $\mathrm{ZnZ} 5$ zeolite was subjected to calcination following the seven-step procedure mentioned before.

The final catalysts were obtained by individually mixing each zeolite (50 wt $\%$ ) with 30 $\mathrm{wt} \%$ of pseudo-boehmite (70\% $\gamma$-alumina) and $20 \mathrm{wt} \%$ of $\alpha$-alumina ( $20 \% \alpha$-alumina in colloidal dispersion). The resulting mix was subjected to wet extrusion, dried at room temperature for $24 \mathrm{~h}$ and at $110{ }^{\circ} \mathrm{C}$ for $12 \mathrm{~h}$, crushed, sieved $(0.125-0.3 \mathrm{~mm}$ ), and subjected to calcination at $550{ }^{\circ} \mathrm{C}$ for $2 \mathrm{~h}$. This mixing process (agglomeration) was performed in order to provide the catalyst particles with a meso- and microporous matrix that scatters the zeolite crystals, which improves the light olefins selectivity and catalyst lifetime by attenuating the blockage caused by coke at the crystal openings $[48,49]$. Moreover, the zeolite agglomeration is necessary to increase the attrition resistance of catalyst particles.

The chemical composition of the zeolites was determined using X-ray photoelectron spectroscopy (XPS) in a SPECS (Berlin, Germany) equipped with a Phoibos 150 1DDLD analyzer and a monochromic radiation source of $\mathrm{Al} \mathrm{K \alpha}(1486.7 \mathrm{eV})$. The structural 
properties of parent and modified zeolites were determined using X-ray diffraction (XRD) and nuclear magnetic resonance (NMR) of ${ }^{27} \mathrm{Al},{ }^{29} \mathrm{Si}$ and ${ }^{31} \mathrm{P}$. The textural properties of parent and modified zeolites and catalysts were determined using $\mathrm{N}_{2}$ physisorption, and the experimental equilibrium data was used to calculate the porosity parameters using the BET and t-plot methods. We followed routine experimental procedures described elsewhere for all XRD, NMR and $\mathrm{N}_{2}$ physisorption measurements [13].

The acid properties of parent and modified zeolites and corresponding catalysts were determined using Fourier-transform infrared (FTIR) spectroscopy, pyridine adsorption coupled with FTIR spectroscopy (Py-FTIR) and ammonia adsorption and temperatureprogrammed desorption ( $\left.\mathrm{NH}_{3}-\mathrm{TPD}\right)$. FTIR and Py-FTIR measurements were performed in a FTIR spectrometer (Thermo Scientific, Nicolet 6700) with a high temperature high pressure cell (Specac, HTHP) inside of its compartment to place the sample and perform thermal treatments. The sample preparation consisted of pressing $20 \mathrm{mg}$ of powdered zeolite or catalyst applying a pressure of $10 \mathrm{t} \mathrm{cm}^{-2}$ in order to conform a disc of $1.3 \mathrm{~cm}$ in diameter. The experimental procedure consisted of outgassing the sample under vacuum at $450{ }^{\circ} \mathrm{C}$ for $90 \mathrm{~min}$ with a ramp rate of $10{ }^{\circ} \mathrm{C} \mathrm{min}-1$. Afterward, the sample is cooled down and stabilized at $400{ }^{\circ} \mathrm{C}$, and a sample spectrum is recorded subtracting the background spectrum of the empty HTHP cell. Then, the sample is cooled down and stabilized at $150{ }^{\circ} \mathrm{C}$, and a background spectrum is recorded. The sample is exposed to pyridine (Sigma-Aldrich, 99.8\%) following this procedure: (1) dosing pyridine for $1 \mathrm{~min}$, (2) equilibrating pyridine adsorption for $5 \mathrm{~min}$, (3) outgassing pyridine physiosorbed for 3 min and (4) recording a sample spectrum subtracting the background spectrum of the sample at $150{ }^{\circ} \mathrm{C}$. This procedure is repeated until achieving saturation of the sample.

Ammonia adsorption measurements were performed in a combined thermogravimetry and differential scanning calorimetry (TG-DSC) apparatus (Setaram). The experimental procedure consisted of outgassing $30 \mathrm{mg}$ of zeolite sample or $60 \mathrm{mg}$ of catalyst sample under He flow at $550^{\circ} \mathrm{C}$ for $30 \mathrm{~min}$ with a ramp rate of $10^{\circ} \mathrm{C} \mathrm{min}{ }^{-1}$. Afterward, the sample is cooled down and stabilized at $150{ }^{\circ} \mathrm{C}$ and exposed to $50 \mu \mathrm{L} \mathrm{min}{ }^{-1}$ of ammonia until achieving saturation determined by the stabilization of TG and heat flow signals. The ammonia-saturated sample is outgassed in order to remove ammonia physiosorbed and the amount of ammonia chemisorbed is calculated from TG and heat flow experimental data. The ammonia TPD measurements were performed in a chemisorption analyzer (Micromeritics, AutoChem II 2920). The experimental procedure consisted of outgassing 60-120 mg of zeolite or catalyst sample and exposing it to ammonia following the same procedure previously described. Then, the sample is heated up to $550{ }^{\circ} \mathrm{C}$ with a ramp rate of $5{ }^{\circ} \mathrm{C} \mathrm{min}-1$ under He flow, and the ammonia desorbed is analyzed with a thermal conductivity detector. 


\subsection{Fixed-bed reactor}

The MTO reaction was carried out in a fixed-bed reactor operated as an integral laboratory reactor. Figure S1 shows a diagram of the experimental setup. Briefly, the reactor is inside of a furnace that allows heating the fixed-bed isothermally at the desired reaction temperature. The reactor and the furnace are inside of a hot box kept at $200{ }^{\circ} \mathrm{C}$ that allows heating affluent and effluent streams. The effluent stream, carrying all reaction products in gas-vapor phase, is split by means of a sample loop. The gas-vapor phase products passing through the sample loop are carried with He in a heated line to a microgas chromatograph (Varian, CP4900). For the gas-phase product analysis, three commercial columns were used: (1) Molesieve $5 \AA$ for the separation of small molecules such as $\mathrm{N}_{2}, \mathrm{O}_{2}, \mathrm{CO}$ and $\mathrm{CH}_{4}$, operated at a column temperature of $45^{\circ} \mathrm{C}$, column injection temperature of $65^{\circ} \mathrm{C}$ and column pressure of $26 \mathrm{psi}$; (2) PoraPLOT Q for the separation of $\mathrm{C}_{1}-\mathrm{C}_{4}$ hydrocarbons, operated at a column temperature of $80^{\circ} \mathrm{C}$, column injection temperature of $80^{\circ} \mathrm{C}$ and column pressure of $26 \mathrm{psi}$; and (3) $\mathrm{CP}$-Sil $5 \mathrm{CB}$ for the separation of $\mathrm{C}_{4}-\mathrm{C}_{10}$ hydrocarbons and oxygenates, operated at a column temperature of $80^{\circ} \mathrm{C}$, column injection temperature of $80^{\circ} \mathrm{C}$ and column pressure of $26 \mathrm{psi}$.

The feed consists of liquid methanol (Sigma-Aldrich, 99.8\%) pumped at $0.1 \mathrm{~mol} \mathrm{~h}^{-1}$ and carried with $15 \mathrm{~mol} \%$ of $\mathrm{He}$, which it is vaporized in the hot box. In a typical experiment, the reactor is loaded with a solid mixture of catalyst and silicon carbide (VWR Chemicals, particle size $<0.105 \mathrm{~mm}$ ) forming a bed of $6 \mathrm{~cm}^{3}$. The catalyst is outgassed at $400{ }^{\circ} \mathrm{C}$ for $1 \mathrm{~h}$ with a ramp rate of $10{ }^{\circ} \mathrm{C} \mathrm{min}^{-1}$ in $30 \mathrm{~mL} \mathrm{~min}^{-1}$ of $\mathrm{He}$ and at 1.85 bar. Afterward, the feed is switched to methanol giving rise to its conversion at $400{ }^{\circ} \mathrm{C}$ and 1.85 bar. We varied the catalyst weight in each run, in order to test different space time values (W/F). The MTO reaction is stopped after a giving time on stream (TOS) by cutting off the methanol feed and cooling down the reactor rapidly. The spent catalyst is removed from the reactor and analyzed.

The amount and characterization of products trapped in the catalyst are determined using thermogravimetric analysis (TGA) and extraction of trapped products. The TGA measurements were performed in a thermobalance (TA Instruments, Q5000) carrying out two consecutive runs: (1) a temperature-programmed desorption (TPD), and (2) a temperature programmed oxidation (TPO). The experimental procedure consisted of rapidly outgassing $15 \mathrm{mg}$ of sample at $200^{\circ} \mathrm{C}$ for $20 \mathrm{~min}$ in order to avoid the loss of any trapped hydrocarbon. Afterward, the TPD started at a ramp rate of $10{ }^{\circ} \mathrm{C} \mathrm{min}^{-1}$ in $50 \mathrm{~mL}$ $\mathrm{min}^{-1}$ of He up to $550{ }^{\circ} \mathrm{C}$ for $1 \mathrm{~h}$. Then, the sample is cooled down and stabilized at 200 ${ }^{\circ} \mathrm{C}$ and the flow is switched to air at $50 \mathrm{~mL} \mathrm{~min}^{-1}$. Once stabilized, the TPO started at a ramp rate of $10{ }^{\circ} \mathrm{C} \mathrm{min}^{-1}$ up to $550{ }^{\circ} \mathrm{C}$ for $90 \mathrm{~min}$. 
The extraction of trapped products is adapted from the standard procedure developed by Guisnet and coworkers.[50] The experimental procedure consisted of dissolving $30 \mathrm{mg}$ of sample in $2.4 \mathrm{~mL}$ of hydrofluoric acid (Merck, 40\%) in a Teflon container for $1 \mathrm{~h}$. Afterward, the acid solution is neutralized with a sodium hydroxide (Panreac, pure) solution ( $1 \mathrm{M})$. The extraction of hydrocarbons is performed adding $2 \mathrm{~mL}$ of dichloromethane (Sigma-Aldrich, 99.8\%), shaking for $1 \mathrm{~min}$, decanting for $10 \mathrm{~min}$ and separating the organic and aqueous phases. This extraction procedure is repeated three times to assure the extraction of all soluble hydrocarbons in dichloromethane. The organic phase is then analyzed in a gas chromatograph coupled with a mass spectrometer (Shimadzu, GCMS-QP2010S) in order to identify the soluble hydrocarbons trapped in the catalyst.

\subsection{Operando reactors}

To obtain a further insight on the performance of modified catalysts, the MTO reaction is also performed in operando FTIR and UV-vis spectroscopies. The operando FTIR spectroscopy setup is similar to that previously described for FTIR and Py-FTIR measurements. The operando UV-vis spectroscopy setup consists of a catalytic cell (Linkam, THMS600 Stage) connected to a system controller (Linkam, PE95/T95) and inside of an adapted compartment (Jasco, ARN-915i) of a UV-vis-NIR spectrometer (Jasco, V-780). The spectrum measurements are made using an integrating sphere placed on the catalytic cell window. In both experiments, the sample preparation is similar to that previously described for FTIR and Py-FTIR measurements. The feed consisted of a $\mathrm{N}_{2}$ gas flow saturated with methanol vapor. For this, a determined flowrate of $\mathrm{N}_{2}$ is fed to a methanol saturator controlled at a determined temperature $\left(\sim 1{ }^{\circ} \mathrm{C}\right.$ for $\mathrm{UV}$-vis or 25 ${ }^{\circ} \mathrm{C}$ for FTIR), so that the methanol concentration is given by its thermodynamic equilibrium at the saturator temperature.

The experimental procedure of both operando spectroscopies consisted of outgassing the catalyst under vacuum and at $550{ }^{\circ} \mathrm{C}$ for $1 \mathrm{~h}$ with a ramp rate of $10{ }^{\circ} \mathrm{C} \mathrm{min}{ }^{-1}$. Afterward, the catalyst is cooled down and stabilized at $400{ }^{\circ} \mathrm{C}$ under $\mathrm{N}_{2}$ flow, and a background spectrum is recorded. The MTO reaction is performed in continuous operation by switching the $\mathrm{N}_{2}$ flow to the feed flow for $2 \mathrm{~h}$ on stream and recording spectra at intervals of $150 \mathrm{~s}$ (FTIR) or $65 \mathrm{~s}$ (UV-vis). We used different conditions of space time and methanol partial pressure due to the different detection limits of each spectroscopic technique. UV-vis spectroscopy is highly sensitive to the sample color and the rapid coke formation darkens the sample making difficult to record appropriate spectra. After performing experimental tests, we came to conclusion that operando UV-vis spectroscopy measurements should be carried out at five times the value of the equivalent space time used for operando FTIR spectroscopy measurements. 


\section{RESULTS}

\subsection{Catalyst characterization}

The chemical composition of the zeolite samples was determined using $\mathrm{x}$-ray photoelectron spectroscopy (XPS). Table 1 summarizes the chemical composition of the parent HZ5 and modified PZ5 and ZnZ5 zeolites. The P and Zn contents are 0.919 and $2.22 \mathrm{wt} \%$ for the PZ5 zeolite and ZnZ5 zeolites, respectively. The P content is lower than the nominal one calculated to be $1.00 \mathrm{wt} \%$, which indicates the loss of $\mathrm{P}$ species during the calcination process of the PZ5 zeolite and an overall impregnation efficiency of 91.9\%. The $\mathrm{HZ} 5$ and $\mathrm{ZnZ5}$ zeolites have $\mathrm{SiO}_{2} / \mathrm{Al}_{2} \mathrm{O}_{3}$ molar ratios similar to the nominal one for the starting commercial zeolite $\left(\mathrm{SiO}_{2} / \mathrm{Al}_{2} \mathrm{O}_{3}=80.0\right)$. However, the PZ5 zeolite has a higher $\mathrm{SiO}_{2} / \mathrm{Al}_{2} \mathrm{O}_{3}$ molar ratio (118), which indicates an apparent preferential dealumination caused by the $\mathrm{H}_{3} \mathrm{PO}_{4}$ treatment that is in agreement with previous results [31]. Furthermore, based on these observations, the calculated P/Al and $\mathrm{Zn} / \mathrm{Al}$ molar ratios for the corresponding zeolites are 1.0 and 0.85 , respectively.

Table 1. Chemical composition of the parent and modified zeolites determined by using XPS.

\begin{tabular}{|l|l|l|l|}
\hline & $\mathrm{HZ5}$ & $\mathrm{PZ5}$ & $\mathrm{ZnZ5}$ \\
\hline $\mathrm{Al}, \mathrm{wt} \%$ & 48.9 & 47.2 & 45.4 \\
\hline $\mathrm{Si}, \mathrm{wt} \%$ & 1.17 & 0.772 & 1.08 \\
\hline $\mathrm{P}, \mathrm{wt} \%$ & - & 0.919 & - \\
\hline $\mathrm{Zn}, \mathrm{wt} \%$ & - & - & 2.22 \\
\hline $\mathrm{SiO}_{2} / \mathrm{Al}_{2} \mathrm{O}_{3}, \mathrm{~mol} \mathrm{~mol}^{-1}$ & 80.7 & 118 & 81.3 \\
\hline $\mathrm{X} / \mathrm{Al}^{(\mathrm{a})}, \mathrm{mol} \mathrm{mol}^{-1}$ & - & 1.03 & 0.853 \\
\hline
\end{tabular}

(a) Where $\mathrm{X}=\mathrm{P}$ or $\mathrm{Zn}$.

The structural properties of the zeolite samples were determined by using $\mathrm{x}$-ray diffraction (XRD) and nuclear magnetic resonance (NMR) spectroscopies. Figure 1 depicts the XRD patterns of the parent HZ5 and modified PZ5 and ZnZ5 zeolites. All samples have characteristic peaks of the ZSM-5 crystalline structure, according to the International Zeolite Association (IZA) database. The main distinctive peaks are centered at $8.18,9.07,23.3,24.1$ and $24.6^{\circ}$. The results indicate that the modifiers do not cause significant changes in the ZSM-5 crystalline structure. However, both modifiers reduce the ZSM-5 crystallinity indicated by the low intensity of the main XRD peaks for the PZ5 and ZnZ5 zeolites in comparison with the parent HZ5 zeolite. The crystallinity loss can 
be estimated by calculating the ratio between the sum of intensities of the main XRD peaks for the modified and the parent zeolite $\left(R_{C}\right)$ :

$$
R_{C}=\frac{\left(I_{8.18}+I_{9.07}+I_{23.3}+I_{24.1}+I_{24.6}\right)_{\text {modified }}}{\left(I_{8.18}+I_{9.07}+I_{23.3}+I_{24.1}+I_{24.6}\right)_{\text {parent }}}
$$

Where $I_{i}$ is the intensity of the XRD peak at the specified diffraction angle. The results give 0.80 and 0.67 for the PZ5 and ZnZ5 zeolites, indicating that the $\mathrm{Zn}$ modification causes the major crystallinity loss. Ji et al. [51] also observed the decrease of a similar crystallinity indicator for P-modified ZSM-5 zeolites and pointed out that the crystallinity loss is due to defects caused by dealumination of the framework ( $\mathrm{P}$ species interacting with Al). Bi et al. [38] reported similar values for the crystallinity loss of Zn-modified ZSM-5 zeolites and attributed this to the location of $\mathrm{Zn}$ species in the main channels of the zeolite causing a partial breakdown of the skeletal structure. Niu et al. [36] attributed the crystallinity loss of Zn-modified ZSM-5 zeolites to the intermixing of Zn species with the zeolite.

\section{Figure 1.}

Figures 2a depicts the ${ }^{27} \mathrm{Al}$ NMR spectra of the parent HZ5 and modified PZ5 and ZnZ5 zeolites. These spectra show a very intense resonance band at $\sim 55 \mathrm{ppm}$ corresponding to tetra-coordinated aluminium $\left(\mathrm{Al}^{\mathrm{IV}}\right)$ in the zeolite framework and a weak resonance band at $\sim 0$ and $-11 \mathrm{ppm}$ corresponding to hexa-coordinated aluminium $\left(\mathrm{Al}^{\mathrm{VI}}\right)$ in the zeolite extra-framework [52-54]. The $\mathrm{Al}^{\mathrm{IV}}$ species are predominant in all zeolites but they decrease with $\mathrm{P}$ modification in favor of $\mathrm{Al}^{\mathrm{VI}}$ species coordinated with $\mathrm{P}(-11 \mathrm{ppm})$, which is due to the partial exclusion of $\mathrm{Al}$ from the zeolite framework [25,28,31-34]. At the same time, the band of $\mathrm{Al}^{\mathrm{IV}}$ species can be sub-deconvoluted into two [55]: (i) $56 \mathrm{ppm}$, strong acid sites sometimes involving a pair of closed $\mathrm{Al}^{\mathrm{IV}}$ (Al-O-Si-OAl), located within the micropores of the H-ZSM-5 zeolite (both straight and sinusoidal pores), referred as $(\alpha+\gamma)$ siting; and (ii) 53 ppm, weaker acid sites, involving a single $\mathrm{Al}^{\mathrm{IV}}$ site, located within the pore intersections and referred as $\beta$ siting. The PZ5 zeolite shows that the dealumination performed by the $\mathrm{H}_{3} \mathrm{PO}_{4}$ is more selective towards the $\mathrm{Al}$ sites of the intersections $\left(\mathrm{Al}^{\mathrm{IV}-53}\right)$, deflecting the strongest acid sites of the sinusoidal channels $\left(\mathrm{Al}^{\mathrm{IV}-}\right.$ ${ }^{56}$ ). The ZnZ5 zeolite shows, in contrast, that the balance of Al sites has shifted towards a higher proportion of sites in the intersections. As this ZnZ5 zeolite has not suffered dealumination (Table 1), the effect of the modifier on the Al environment can be ascribed to rearmament of $\mathrm{Al}$ siting within the zeolite framework.

Figures $2 \mathrm{~b}$ depicts the ${ }^{29} \mathrm{Si}$ NMR spectra of the parent HZ5 and modified PZ5 and ZnZ5 zeolites. All zeolites show a resonance band at $\sim-115 \mathrm{ppm}$ that can be unequivocally 
assigned to $\mathrm{Q}^{4}$ species of the type $\mathrm{Si}(\mathrm{OSi})_{4}[31,54]$. Other band assignations are uncertain. The bands between -104.8 and -103.5 ppm may be attributable to $\mathrm{Q}^{4}$ species with one $\mathrm{Si}$ atom substituted for an $\mathrm{Al}$ atom in the second coordination sphere $\left[\mathrm{Si}(\mathrm{OSi})_{3}(\mathrm{OAl})\right]$ or $\mathrm{Q}^{3}$ species that have an hydroxyl terminal group $\left[\left(\mathrm{Si}(\mathrm{OSi})_{3}(\mathrm{OH})\right)\right]$. The ${ }^{29} \mathrm{Si}$ NMR spectrum of the PZ5 zeolite shows a relative decrease of the $\mathrm{Si}(\mathrm{OSi})_{3}(\mathrm{OAl})$ species $(-104.8 \mathrm{ppm})$ accounting for the preferential dealumination (Table 1) in this zeolite. The ${ }^{29} \mathrm{Si} \mathrm{NMR}$ spectrum of the ZnZ5 zeolite shows more intense resonance bands in general but relatively similar overall profile as for the parent zeolite. These observations indicates that the $\mathrm{Zn}$ modification does not cause selective dealumination or desilication of the zeolite and the higher intensity observed may contribute to $\mathrm{Zn}$ cations interacting with $\mathrm{Si}$ atoms in their second coordination sphere [56].

\section{Figure 2.}

The textural properties of zeolite samples were determined using $\mathrm{N}_{2}$ physisorption. Table 2 summarizes the specific surface area of total pores $\left(\mathrm{S}_{\mathrm{BET}}\right)$, micropores $\left(\mathrm{S}_{\text {micro }}\right)$ and mesopores $\left(\mathrm{S}_{\text {meso }}\right)$. The $\mathrm{S}_{\mathrm{BET}}$ decreases with $\mathrm{P}$ and $\mathrm{Zn}$ modifications. The $\mathrm{S}_{\text {meso }}$ remains relatively constant for modified zeolites whereas the $\mathrm{S}_{\text {micro }}$ decreases and it is the responsible for the decrease of the $\mathrm{S}_{\text {ВET}}$. These results can be ascribed to the simultaneous desilication and dealumination occurred in P modified zeolite (Table 1 and Figure 1), and the framework rearrangement occurred in the $\mathrm{Zn}$ modified one. In both cases, these effects partially impede the $\mathrm{N}_{2}$ uptake in the zeolite micropores. The similar observations reported in the literature for P modified H-ZSM-5 zeolites have been associated with the fact that extra-framework ( $\mathrm{P}-\mathrm{Al}$ species as seen in Figure 2a, band at $-11 \mathrm{ppm}$ ) partially occlude the zeolite micropores [25]. On the other hand, the $\mathrm{Zn}$ incorporation into the zeolite framework is reported to reduce the accessibility of micropores [36]. Therefore, the area of micropores follows the trend HZ5 $>$ ZnZ5 $>$ PZ5, whereas the area of mesopores remains virtually unmodified.

Table 2. Textural properties of the parent and modified zeolites measured using $\mathrm{N}_{2}$ physisorption.

\begin{tabular}{|l|l|l|l|}
\hline & HZ5 & PZ5 & ZnZ5 \\
\hline $\mathrm{S}_{\mathrm{BET}}{ }^{(\mathrm{a})}\left(\mathrm{m}^{2} \mathrm{~g}^{-1}\right)$ & 434 & 359 & 389 \\
\hline $\mathrm{S}_{\text {micro }}{ }^{(\mathrm{b})}\left(\mathrm{m}^{2} \mathrm{~g}^{-1}\right)$ & 366 & 290 & 323 \\
\hline $\mathrm{S}_{\text {meso }}\left(\mathrm{m}^{2} \mathrm{~g}^{-1}\right)$ & 68.0 & 69.0 & 66.0 \\
\hline
\end{tabular}

(a) Determined using the BET method. (b) Determined using the t-plot method. 
The acid properties of the zeolite samples and catalysts were determined measuring the Fourier transform infrared (FTIR) spectra of bare zeolites and with adsorbed pyridine and using the temperature programmed desorption (TPD) of ammonia. Figure 3a depicts the FTIR spectra in the $\mathrm{O}-\mathrm{H}$ stretching vibration region of parent and modified zeolites at $400{ }^{\circ} \mathrm{C}$ and under vacuum. All the zeolites show three main bands at $3600,3680,3718$ and $3734 \mathrm{~cm}^{-1}$, and these bands respectively correspond to [32-34,36,39,57]: bridged hydroxyl groups accounting for strong BAS, hydroxyl groups connected to extraframework aluminum and silanol groups on the internal and external surface. Additionally, the PZ5 zeolite shows a band at $3665 \mathrm{~cm}^{-1}$, which corresponds to hydroxyl groups interacting with $\mathrm{P}$ ( $\mathrm{P}-\mathrm{OH}$ species) [32]. The modification with $\mathrm{P}$ causes a decrease of silanol groups in benefit of extra-framework hydroxyl groups, in agreement with the ${ }^{29} \mathrm{Si}$ NMR results (Figure 1c). On the other hand, the modification with $\mathrm{Zn}$ causes a decrease of BAS and internal silanol groups. These observations agree with the dealumination provoked by the $\mathrm{H}_{3} \mathrm{PO}_{4}$ and the exchange of $\mathrm{Zn}$ cationic species prompted by $\mathrm{ZnCl}_{2}$. Therefore, we can outline the following trend of BAS concentration in the zeolites: HZ5 > PZ5 > ZnZ5.

The nature of acid sites of the zeolite samples was determined using pyridine adsorption couple with FTIR spectroscopy (Py-FTIR). The spectra of pyridine-saturated zeolites (Figure $3 \mathrm{~b}$ ) give rise to the characteristic bands of pyridine interacting with BAS at 1545 $\mathrm{cm}^{-1}$ and with LAS at $1455 \mathrm{~cm}^{-1}$. The area of these bands is proportional to the concentration of BAS and LAS ( $\mathrm{n}_{\text {BAS }}$ and $\mathrm{n}_{\mathrm{LAS}}$, respectively) according to the Beer-

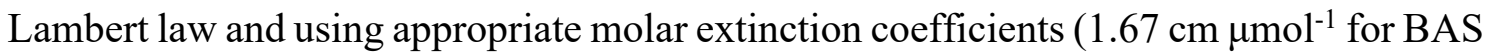

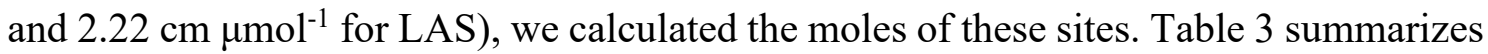
the results obtained for the calculations. The $\mathrm{P}$ or $\mathrm{Zn}$ modifications cause different effects on the nature of acid sites. The PZ5 zeolite shows decrements of BAS and LAS of -5\% and $-66 \%$, respectively, indicating that the modification caused by $\mathrm{H}_{3} \mathrm{PO}_{4}$ is severer on LAS than on BAS. All these observations are aligned with previous works using $\left(\mathrm{NH}_{4}\right)_{2} \mathrm{HPO}_{4}$ or $\mathrm{H}_{3} \mathrm{PO}_{4}$ as modifiers and when the $\mathrm{P}$ content exceeds $0.5 \mathrm{wt} \%[34,51,58]$. Other works have reported a more significant BAS decrement for H-ZSM-5 zeolites modified with $\mathrm{H}_{3} \mathrm{PO}_{4}$, of $-71 \%$ [34] or $-35 \%$ [32]. However, the lower decrement of BAS concentration observed in this work relates to the fact that $\mathrm{P}-\mathrm{OH}$ species also behaves as BAS. This is evident when we compare the spectra of bare and pyridine-saturated PZ5 zeolite in the $\mathrm{O}-\mathrm{H}$ stretching vibration (Figure S2), which indicates that the $3665 \mathrm{~cm}^{-1}$ band disappears after exposing the PZ5 zeolite to pyridine. Thus, the BAS band observed for the PZ5 zeolite has a contribution of pyridine interacting with both $\mathrm{Al}-\mathrm{OH}$ and $\mathrm{P}-\mathrm{OH}$ sites. The intrinsic vibration frequencies in the $3500-3800 \mathrm{~cm}^{-1}$ range suggests that the former has stronger acidity than the latter.

\section{Figure 3.}


On the other hand, the ZnZ5 zeolite shows a BAS decrement of $-47 \%$ (Table 3) and LAS increment of $+430 \%$. Many authors have reported a similar trend for $\mathrm{Zn}$ modified zeolites regardless of the precursor salt used [35,36,38,59]. The incorporation of $\mathrm{Zn}$ occurs via ion exchange causing the loss of BAS. However, the $\mathrm{Zn}$ species attached to BAS can accept a pair of electrons, i.e. it becomes an apparent LAS. In fact, the band at $1614 \mathrm{~cm}^{-1}$ in the Py-FTIR spectrum is attributable to pyridine coordinated with $\mathrm{Zn}$ cations as apparent LAS [38]. It is noteworthy to mention that the excessive amount of LAS estimated from our Py-FTIR results may be due to using incorrect molar extinction coefficients for the coordination of pyridine with these new LAS arising from $\mathrm{Zn}$ species.

Table 3. Concentrations of acid sites by nature and strength in the parent and modified zeolites.

\begin{tabular}{|c|c|c|c|}
\hline & HZ5 & PZ5 & ZnZ5 \\
\hline $\mathrm{n}_{\mathrm{LAS}}{ }^{(\mathrm{a})}\left(\mu \mathrm{mol} \mathrm{g}^{-1}\right)$ & 60.8 & 20.5 & 322 \\
\hline $\mathrm{n}_{\mathrm{BAS}}{ }^{(\mathrm{a})}\left(\mu \mathrm{mol} \mathrm{\textrm {g } ^ { - 1 }}\right)$ & 315 & 300 & 166 \\
\hline Total $^{(\mathrm{a})}\left(\mu \mathrm{mol} \mathrm{g} \mathrm{g}^{-1}\right)$ & 376 & 321 & 488 \\
\hline nWAS $^{(b)}\left(\mu \mathrm{mol} \mathrm{g}^{-1}\right)$ & 23.5 & 30.0 & 38.1 \\
\hline $\left.\mathrm{n}_{\mathrm{MAS}^{(\mathrm{b})}(\mu \mathrm{mol} \mathrm{g}}{ }^{-1}\right)$ & 60.5 & 140 & 198 \\
\hline $\mathrm{n}_{\mathrm{SAS}}{ }^{(\mathrm{b})}\left(\mu \mathrm{mol} \mathrm{g^{-1 } )}\right.$ & 245 & 146 & 75.3 \\
\hline Total $^{(\mathrm{b})}\left(\mu \mathrm{mol} \mathrm{g}{ }^{-1}\right)$ & 329 & 316 & 311 \\
\hline
\end{tabular}

(a) Determined by deconvolution of FTIR spectra of pyridine-saturated samples and calculations using molar extinction coefficients. (b) Determined by integrating the TPD profiles into the following ranges: WAS $=150-200{ }^{\circ} \mathrm{C}, \mathrm{MAS}=200-300{ }^{\circ} \mathrm{C}$ and $\mathrm{SAS}=$ $300-550{ }^{\circ} \mathrm{C}$.

The acid site concentration and distribution by strength of the zeolite samples were determined by $\mathrm{NH}_{3}$-TPD measurements (Figure S3). We determined the distribution of acid sites by integrating the TPD profiles into three regions, following a methodology previously described in the literature [36]: $150-200{ }^{\circ} \mathrm{C}$, weak acid sites (WAS); 200-300 ${ }^{\circ} \mathrm{C}$, medium acid sites (MAS); and 300-550 ${ }^{\circ} \mathrm{C}$, strong acid sites (SAS). Table 3 summarizes the results obtained for the concentration of WAS, MAS and SAS (nWAS, $\mathrm{n}_{\text {MAS }}$ and $\mathrm{n}_{\mathrm{SAS}}$, respectively). The total number of acid sites only drops $4.0 \%$ and $5.5 \%$ by the $\mathrm{P}$ or $\mathrm{Zn}$ modifications, respectively. In both cases, the decrement is due to the interconversion of SAS into MAS, with a loss of 40 and $69 \%$ of SAS in the PZ5 and ZnZ5 zeolites, respectively. When we compare the acid site distribution by strength with the acid site nature, it is noticeable that both $\mathrm{P}$ and $\mathrm{Zn}$ modifications weaken the acid strength of sites in the zeolite, but they have a different effect on the acid site nature. Acid sites interacting with $\mathrm{P}$ species keep their Brønsted nature while $\mathrm{Zn}$ species convert BAS into 
LAS. Thus, the MAS and SAS are linked with BAS in the PZ5 zeolite, while MAS are linked with the apparent LAS in the ZnZ5 zeolite.

\subsection{Fixed-bed reactor}

\subsubsection{Initial kinetic performance}

The reaction products are grouped into: (1) light gas (LG), corresponding to methane and carbon dioxide; (2) light paraffins (LP), including ethane, propane and traces of butanes; (3) light olefins (LO), that is, ethylene, propylene and butenes; (4) $\mathrm{C}_{5+}$ "heavy" aliphatics (HA), which are isomers of $\mathrm{C}_{5}-\mathrm{C}_{9}$ paraffins and olefins; and (5) aromatics, mostly benzene, toluene and xylenes (BTX). We also observed methanol dehydration products such as dimethyl ether and water in the effluent stream. On the basis that methanol and dimethyl ether react to form hydrocarbons $[11,60]$, we defined the conversion of oxygenates $(x)$ as the fraction of carbon-based moles of methanol and dimethyl ether reacted:

$$
x=\frac{F_{O, \text { in }}-F_{O, o u t}}{F_{O, \text { in }}}
$$

where $F_{0, \text { in }}$ is the carbon-based molar flowrate of methanol in the feed stream and $F_{0, \text { out }}$ is the carbon-based molar flowrate of methanol and dimethyl ether in the reactor effluent stream. Accordingly, the yield $\left(Y_{i}\right)$ and selectivity $\left(S_{i}\right)$ of each product $i$ are:

$$
\begin{gathered}
Y_{i}=\frac{F_{i, \text { out }}}{F_{O, \text { in }}} \\
S_{i}=\frac{F_{i, \text { out }}}{F_{O, \text { in }}-F_{O, \text { out }}}=\frac{Y_{i}}{x}
\end{gathered}
$$

where $F_{i, \text { out }}$ is the carbon-based molar flowrate of the $i$ product in the reactor effluent stream.

Figure 4 depicts the performance of HZ5, PZ5 and ZnZ5 catalysts in the MTO reaction in terms of the initial $\left(\mathrm{TOS}_{0}=10 \mathrm{~min}\right.$ ) oxygenates (methanol and dimethyl ether) conversion and products yield at different space time (W/F, h $\left.\mathrm{g} \mathrm{mol}{ }^{-1}\right)$ values. Each data set of conversions was obtained in an uncorrelated experiment using different amounts of catalyst, and therefore, space time values. Figure 4a depicts that the conversion increases with increasing values of space time, following a sigmoidal function typical of autocatalytic processes [61]. That is, for space times of $0.1-0.2 \mathrm{~h} \mathrm{~g} \mathrm{~mol}^{-1}$, the conversion is controlled by the incipient formation of hydrocarbon pool species coming from the direct route of $\mathrm{C}-\mathrm{C}$ formation [14]. Then, the conversion is controlled by hydrocarbon pool species themselves acting, together with acid sites, as active sites. The ZnZ5 catalyst shows remarkably slower initiation and hydrocarbon pool controlled kinetic steps. Figure 
$4 \mathrm{~b}$ compares the evolution of conversion with the BAS-based space time ( $\mathrm{n}_{\mathrm{BAS}} / \mathrm{F}, \mathrm{h} \mu \mathrm{mol}$ $\mathrm{mol}^{-1}$ ), as determined by Py-FTIR measurements. The results of Figure $4 \mathrm{~b}$ indicate that Zn modification slows down both kinetic steps, which excludes the possible effect of $\mathrm{n}_{\mathrm{BAS}}$ observed for this catalyst. On the contrary, PZ5 catalyst shows similar kinetic performance and any decrease of conversion is attributable to the lower $\mathrm{n}_{\mathrm{BAS}}$.

\section{Figure 4.}

Figure 5 depicts the evolution of the different products yields vs. conversion at $\mathrm{TOS}_{0}$. Under similar conversion levels (variable space time), the parent and modified catalysts show similar LO yield at any conversion level. However, the distribution of species within the LO lump and the yields of other products are different. At the same conversion, the ZnZ5 catalyst shows significantly lower yields of LP and BTX, while higher yield of HA. Thus, Zn modification seems to favor the oligomerization over the hydrogen transfer reactions, in agreement with previous results $[38,40]$. Besides and more importantly, the ZnZ5 catalyst enhances the yield of propylene $(\mathrm{P})$ and decreases the ethylene one (E) at high conversion values. At conversion 0.95 , the selectivity within the olefin pool $\left(\mathrm{C}_{2}-\mathrm{C}_{5+}\right)$ in the PZ5 and HZ5 catalysts are relatively similar with slight increase of ethylene and propylene for the former catalyst. The ZnZ5 catalyst shows a slightly higher selectivity of propylene, butenes and HA and at the same time lower selectivity of propane, butanes and aromatics.

These observations reassure the higher dominance of the olefin cycle and the oligomerization/cracking mechanisms over the hydrogen transfer that leads to paraffins and aromatics. The ZnZ5 catalyst shows much higher selectivity of propylene than that of ethylene (with an increase of $51 \%$ in the ratio of propylene/ethylene selectivity), which has been a recurrent effort in the literature [62]. However, there is still a lack of agreement if this ratio is controlled by the olefin/aromatic ratio in the hydrocarbon pool species or any other kinetic event [6]. Ilias et al. [63] defined the ratio of selectivity ethylene/isobutane as representative of the propagation of the aromatic cycle over the olefinic one. For the conditions depicted in Figure 5 at conversion 0.95, these ratios are: 3.4-3.5 for the HZ5 and PZ5 catalysts and 2.9 for ZnZ5 catalyst. Thus, this ratio also proves the higher predominance of the olefinic cycle within the ZnZ5 catalyst at identical conversion level. Accounting all selectivity performance, the ZnZ5 catalyst is remarkably interesting for the industrial perspective [12].

\section{Figure 5.}

\subsubsection{Deactivation kinetic performance}

To determine the effect of the $\mathrm{P}$ or $\mathrm{Zn}$ modifications on the catalyst deactivation, we studied the catalyst stability in terms of the evolution with time on stream (TOS) of the 
conversion the coke content. Figure 6a depicts the results for the three catalysts working at the same space time, whereas Figure $6 \mathrm{~b}$ depicts the results when the initial conversion of the catalysts is equalized (using different space time values). The coke content was obtained by repeating the same reaction runs, stopping the run after the indicated TOS, and analyzing the spent catalyst by temperature programed desorption and oxidation (TPD and TPO, respectively). These repetitions verify the high reproducibility of the results presented in terms of the evolution of conversion with TOS. The TPD and TPO profiles (Figures S4 and S5) indicate that the nature of coke is very similar for all catalysts. The TPD profiles show three desorption events at 348,467 and $526{ }^{\circ} \mathrm{C}$. The first peak appears for the HZ5 and PZ5 catalysts at the beginning of reaction and disappears, whereas the peaks at 467 and $526^{\circ} \mathrm{C}$ appear for all catalysts and remain steady over the TOS. All the TPD species can be regarded as product intermediates and hydrocarbon pool species. Then TPO profiles show a unique combustion event at $546{ }^{\circ} \mathrm{C}$, assigned to coke comprised of polycyclic aromatic species.

One of the main observations from Figure 6 is that the ZnZ5 catalyst has a higher stability and a lower coke formation. For example, at similar space times (Figure 6a), the area under the conversion curve, which is the total amount of methanol and dimethyl converted, is higher for the ZnZ5 catalyst than for the PZ5 and HZ5 counterparts. This result is even more significant at the same initial conversion level (Figure 6b). Besides, the value of TOS at which the conversion decrease down to $10 \%\left(\operatorname{TOS}_{10}\right)$ for the same space time value decreases in the following order: ZnZ5 $(17.7 \mathrm{~h})>$ PZ5 $(13.9 \mathrm{~h})>\mathrm{HZ5}$ $(13.1 \mathrm{~h})$, whereas that trend for the same initial conversion level is more dramatic: ZnZ5 $(17.7 \mathrm{~h})>\mathrm{PZ5}(11.2 \mathrm{~h})>\mathrm{HZ} 5(10.8 \mathrm{~h})$. That is, the ZnZ5 catalyst shows an increase of its lifetime (in comparison with the parent catalyst) for the scenarios of Figure $5 \mathrm{a}$ and $5 \mathrm{~b}$ of $35 \%$ and $64 \%$, respectively, whereas these values for PZ5 are $6 \%$ and $4 \%$, respectively.

The coke content evolves in Figure 6 through two consecutive steps [64]: (1) acid site poisoning and (2) pore blockage. The first step dominates at TOS $<2 \mathrm{~h}$ or coke content $<8 \mathrm{mg} \mathrm{g}^{-1}$ and involves the degradation of hydrocarbon pool species on the acid sites $[11,20]$, whereas the second step controls the deactivation in these values of TOS and coke content forward. Taking the last value of coke content and its corresponding TOS, for the experimental set at the same initial conversion, the coke formation rate drops from 3.6 down to $1.5 \mathrm{mg} \mathrm{h}^{-1} \mathrm{~g}^{-1}$ by comparing HZ5 with ZnZ5 catalysts. That is, a drop of coke formation rate of $58 \%$.

\section{Figure 6.}

Figure 6 also shows that there is a clear correlation between coke formation and catalyst stability, and this confirms the fact that the excessive growth of coke is the main cause of catalyst deactivation in the MTO reaction. Interestingly, the conversion drop becomes 
more pronounced at the inflection point of the coke formation curve, which corresponds with the fastest pore blockage stage. This inflection point is determined by the multilayer deposition of polycyclic aromatics on the surface of the zeolite crystals causing a full blockage of the zeolite micropores. Mores et al. [65,66] determined that polycyclic aromatic species rapidly appear at the edges of a H-ZSM-5 zeolite crystal at which straight channels are in contact with the crystal outer surface and cause their blockage. Their results showed that sinusoidal channels openings take longer to form polycyclic aromatic species that eventually block them, and therefore these channels provide reactant and product molecules with more ways to diffuse inside and outside the crystal. Thus, the evolution of coke depicted in Figure 6 can be ascribed to the formation of coke within the pores of the zeolite (acid site poisoning) and on the outside (pore blockage). Each step could be considered an autocatalytic step or sigmoidal function, but the latter without a clear end in coke content. Nevertheless, the conversion decrement follows a univocal inverse sigmoidal function linked with the pore blocking stage. The Figure S6 shows the evolution of yields as the catalyst deactivates at $\mathrm{W} / \mathrm{F}=0.4 \mathrm{~g} \mathrm{~h} \mathrm{~mol}^{-1}$. This exemplifies the results previously obtained by other authors [67], that the product yield spectrum is predominantly independent of coke formation. Comparing the evolution of coke for HZ5 and PZ5 catalysts in Figures 6a and 6b, we observe similar profiles despite the very different catalyst loadings used in the reactor $\left(\mathrm{W} / \mathrm{F}=0.4\right.$ or $\left.0.8 \mathrm{~g} \mathrm{~h} \mathrm{~mol}^{-1}\right)$, which at the same time enable us to indicate that the coke formation is predominantly independent of the conversion for these catalysts.

\subsubsection{Retained species}

The retained species are associated to hydrocarbon pool species that are active for the MTO reaction and at the same time can promote deactivation. That is, they have different behavior as active or deactivating species according to their nature. Our first approach to study these species was to extract them from the spent catalysts resulting from the deactivation kinetic performance analysis following the conventional extraction methodology for zeolite catalysts [50]. Figure 7a depicts the composition and distribution of the retained species found for a TOS of $30 \mathrm{~min}$ for the three catalysts working under similar initial conversion levels. The main identified species are polyalkylbenzenes and the predominant ones are grouped as trimethylbenzenes (triMB), tetramethylbenzenes (tetraMB) pentamethylbenzene (pentaMB) and hexamethylbenzene (hexaMB). The species comprising olefins and BTX aromatics desorb from the catalyst during the reaction, whereas larger molecules has steric constrictions for being hosted in the micropores [11]. Thus, the large molecules of coke are not hosted by the zeolite, they are deposited on its surface or on the mesopores of the matrix. These species are not analyzed by this technique and represent the insoluble coke fraction. At the same level of initial conversion and time, the parent zeolite has significantly greater proportion of large 
methylbenzenes (mainly hexaMB), whereas the distribution of polyalkylbenzenes in ZnZ5 catalyst is displaced towards small methylbenzenes (with a great proportion of tetraMB). Figure $7 \mathrm{~b}$ depicts the evolution of the main retained species with conversion for the three catalysts working under similar initial conversion levels. The amount of retained methylbenzenes decreases with decreasing conversion for all the catalysts, which is particularly significant for the hexaMB. The fact that hexaMB decrease at high conversions, indicates that these species evolve to form polycyclic aromatics, escaping from the micropores and condensing in the matrix $[9,11,19]$. ZnZ5 catalyst shows a considerably higher proportion of tetraMB at high conversions (Figure $7 \mathrm{~b}$ ) than the other catalysts, which is a relatively methylated species that promotes propylene formation over ethylene one $[11,16,68]$.

On the grounds of the behavior of the methylbenzene species evolution, we correlated the ratio of hexaMB and the rest of the retained species ( $\left.R_{\text {hexamB }}\right)$ with the coke content in Figure 7c. Interestingly, we found two linear correlations between $\mathrm{R}_{\text {hexamB }}$ and coke content for all the catalyst: one for HZ5 and PZ5 catalysts, and a second one for ZnZ5 catalyst. The negative slope of these correlations certifies that hexaMB transform (disappears) into coke (as its amount increase). The most important thing is that for the same level of coke formed, ZnZ5 catalyst is less prone to transform hexaMB into coke. That is, $\mathrm{Zn}$ modification of acid sites is a very efficient method to simultaneously decrease the predominance of undesired secondary reactions such as hydrogen transfer (Figure 5) and aromatic condensation into coke (Figure 7).

\section{Figure 7.}

\subsection{Operando reactors}

To further investigate the formation of hydrocarbon pool and polycyclic aromatic species, we carried out the MTO reaction using operando FTIR and UV-vis-NIR spectroscopies. The following two subsection present the results obtained.

\subsubsection{FTIR operando reactor}

Figure 8 depicts the FTIR spectra evolution with TOS for each catalyst during the MTO reaction in the $\mathrm{C}-\mathrm{H}$ stretching vibration region $\left(2700-3200 \mathrm{~cm}^{-1}\right)$ and the $\mathrm{C}-\mathrm{H}$ bending and $\mathrm{C}=\mathrm{C}$ stretching vibration region $\left(1300-1700 \mathrm{~cm}^{-1}\right)$. The exposure of each catalyst sample to the methanol feed gives rise to the FTIR bands indicated in the figure, which accounts for different hydrocarbon species retained, condensed or adsorbed in or on the catalyst. The bands in the $1300-1700 \mathrm{~cm}^{-1}$ region are mostly attributable to retained and condensed species of aromatic nature, whereas the ones in the $2700-3200 \mathrm{~cm}^{-1}$ region have an important contribution of species adsorbed on the active sites. At the beginning, there is an incipient band rising at $1591 \mathrm{~cm}^{-1}$ and then the rises of the bands at 1456, 1570 
and $1616 \mathrm{~cm}^{-1}$ are predominant. However, the $1616 \mathrm{~cm}^{-1}$ band disappears for prolonged TOS, the 1456 and $1570 \mathrm{~cm}^{-1}$ bands partially lose absorbance, and a new band rises at $1481 \mathrm{~cm}^{-1}$. By performing extraction on the spent catalyst samples at the end of each experiment, we confirmed that the only retained species are monocyclic aromatics ranging from xylenes to hexaMB in all the catalyst. This observation together with the observations of the dynamic of FTIR bands and the literature [69-75] lead us to make the following band assignation: the $\mathrm{C}=\mathrm{C}$ or $\mathrm{C}-\mathrm{H}$ in-plane stretching vibration in the aromatic rings of alkylbenzenes (1591 and $1616 \mathrm{~cm}^{-1}$ ), the joint contribution of polycyclic aromatics and alkylbenzenes (1456 and $\left.1570 \mathrm{~cm}^{-1}\right)$ and polycyclic aromatics $\left(1480 \mathrm{~cm}^{-}\right.$ $\left.{ }^{1}\right)$. Bauschlicher et al. [76] associated the $1480 \mathrm{~cm}^{-1}$ band to the $\mathrm{C}-\mathrm{H}$ in-plane vibration in polycyclic aromatics, and this band displaces toward higher wavenumber and increases in intensity as the molecule becomes larger.

\section{Figure 8.}

The evolution of the FTIR bands depicted in Figure 8 indicates that there is a faster formation of hydrocarbon species in the HZ5 and PZ5 catalysts in comparison with the ZnZ5 counterpart. This evolution is better depicted in Figure 9, with the evolution of the intensity of selected FTIR bands with TOS for all the catalysts. The selected bands are: (i) $1616 \mathrm{~cm}^{-1}$ for the formation and degradation of alkybenzenes; $1570 \mathrm{~cm}^{-1}$ for the formation of highly methylated alkylbenzenes and polycyclic aromatics; and $1481 \mathrm{~cm}^{-1}$ for the formation of vert large polycyclic aromatics. The ZnZ5 catalyst shows slower and lower formation of the $1481 \mathrm{~cm}^{-1}$ band and formation and degradation of the $1616 \mathrm{~cm}^{-1}$ band in comparison with the HZ5 and PZ5 catalysts. These latter catalysts have a similar kinetic behavior; however, the PZ5 catalyst shows slightly slower kinetics. The ZnZ5 catalyst also shows slower formation and degradation of the $1570 \mathrm{~cm}^{-1}$ band. The evolution shows a maximum for a TOS of $150 \mathrm{~min}$ for this catalyst, whereas this maximum occurs for a TOS of $120 \mathrm{~min}$ for the HZ5 and PZ5 catalysts. These results indicate that the lower BAS concentration of the ZnZ5 catalyst slows down the formation and degradation of hydrocarbon pool species, which explains the lower activity and the slower coke formation rate of this catalyst in comparison with its HZ5 and PZ5 counterparts working at the same space time.

\section{Figure 9.}

\subsubsection{UV-vis operando reactor}

Figure 10 depicts the UV-vis spectra evolution with TOS for each catalyst during the MTO reaction. The exposure of any of the catalysts to the methanol feed gives rise to the UV-vis bands indicated in the figure. These bands show the absorption corresponding to electronic transitions in aromatics or olefins, and this proves the dynamics of 
hydrocarbons species retained or condensed in the catalyst. By performing extraction on the spent catalyst samples at the end of each experiment, we confirmed that the only retained species are monocyclic aromatics ranging from xylenes to hexaMB in all the catalyst. Thus, the band assignations according to our observations and the literature are as follow [65,66,77-79]: monoenyl or alkylcyclopentenyl carbocations (324 nm), alkylbenzene carbocations (384 and $412 \mathrm{~nm}$ ) and polycyclic aromatic species in coke (592 and $706 \mathrm{~nm}$ ). In these spectra evolutions, the alkylbenzene carbocationic species (384 and $412 \mathrm{~nm}$ ) are the first ones that appear as hydrocarbon pool species and later on the polycyclic aromatic species (592 and $706 \mathrm{~nm}$ ) start to appear when the hydrocarbon pool species are present at a certain concentration. The spectra after $1350 \mathrm{~s}$ on stream look very much the same for the HZ5 and PZ5 catalyst whereas the intensities are much lower for the ZnZ5 catalyst, particularly in the bands corresponding to highly condensed aromatics in coke.

\section{Figure 10.}

Figure 11 depicts the evolution with TOS of the intensity of relevant UV-vis bands. These bands are the $412 \mathrm{~nm}$ band for the formation of alkylbenzenes and $592 \mathrm{~nm}$ band for the formation of polycyclic aromatics. The experimental data shows kinetic behaviors linked with a sigmoidal function typical of autocatalytic processes. The initiation period is particularly distinguishable in this work due to the careful selection of reaction conditions (low methanol partial pressures and relatively low $\mathrm{N}_{2}$ flow rates), which slow down the reaction rate. As seen in the figure, both modifications cause a delay/slowdown of the formation/growth of both hydrocarbon pool and coke species. This effect is more notorious for ZnZ5 catalyst. In the steady-state approach, the bands reach an apparent maximum for the HZ5 and PZ5 catalysts, whereas there is no an apparent maximum for the ZnZ5 catalyst. This is particularly evident for the $592 \mathrm{~nm}$ band on the ZnZ5 catalyst, which indicates the mush slower formation of polycyclic aromatic species.

Figure 11.

Mores et al. [66] studied the MTO reaction on H-ZSM-5 crystals using operando UV-vis spectroscopy and demonstrated that the formation rate of hydrocarbon pool and polycyclic aromatic species increased for the crystal with the higher BAS density at 400 ${ }^{\circ} \mathrm{C}$. They also observed that less acidic H-ZSM-5 crystals did not exhibit an apparent maximum, which we also observe for our ZnZ5 catalyst with lower BAS concentration. Goetze and Weckhuysen [80] studied the MTO reaction using H-ZSM-5 and Mg-ZSM-5 zeolite catalysts by means of operando UV-vis spectroscopy. They observed the formation of two types of coke along the catalyst bed: a primary coke that comes from the conversion of methanol into olefins and a secondary coke that involves the aromatization of olefins. For $\mathrm{Mg}$ modification, the formation of secondary coke is much 
slower than on the parent catalyst and explained that the olefin aromatization is reduced because of the BAS concentration decrement. Based on these reports and considering that our $\mathrm{Zn}$ modification has a similar behavior to that of $\mathrm{Mg}$, we can attribute the lower formation rate of polycyclic aromatic species to the BAS concentration decrement in this catalyst.

\section{DISCUSSION}

The catalyst characterization results indicate that the modification of H-ZSM-5 zeolite with $\mathrm{H}_{3} \mathrm{PO}_{4}$ leads to the partial dealumination of the framework (Table 1 and Figure 2a). The dealumination transforms framework tetra-coordinated $\mathrm{Al}$ located in the micropore intersections into extra-framework Al species (Figures 2a and 3a). Moreover, the final acidity of the PZ5 zeolite is in overall and in nature similar to that of the parent zeolite (Figures $3 \mathrm{a}$ and 3b, Table 3). However, its Brønsted acidity comes from two sites with different strength: original bridged hydroxyl groups in a $\mathrm{Si}-\mathrm{O}-\mathrm{Al}$ sites that are strong BAS, and hydroxyl groups from $\mathrm{P}$ species that are medium-strength BAS. The only important difference we noticed with other similar works in the literature is the way of $\mathrm{P}$ incorporation in the zeolite.

The MTO reaction runs performed in fixed-bed and operando reactors lead to conclude that the modification with, $\mathrm{H}_{3} \mathrm{PO}_{4}$ simply decreases the reaction rate by slowing down the induction and autocatalytic periods but maintaining a similar deactivation period. Indeed, at similar conversion level or number of BAS, the P modified catalyst behaves similar to the parent counterpart, in terms of oxygenates (methanol and dimethyl ether) conversion (Figure 4) and product distribution (Figure 5).

The modification of H-ZSM-5 zeolite with $\mathrm{ZnCl}_{2}$ does not cause a preferential dealumination or desilication process; instead, they may occur simultaneously up to the same extent. The dealumination balances the framework tetra-coordinated Al toward the micropore intersections of lower acid strength (Figure $2 \mathrm{a}$ ), leaving a catalyst with a much lower Brønsted/Lewis acid site ratio but relatively similar total acidity (Figure 3b, Figure S3 and Table 3). The interaction of $\mathrm{Zn}$ cationic species is responsible for the alterations observed in our NMR results. The literature points to different intrinsic catalytic effect of Zn within Zn-modified ZSM-5 zeolite [35,36,39,59,81-84]. This divergence is due to diverse used preparation methods or modifiers. The oxidation state of $\mathrm{Zn}$ is univocally $\mathrm{Zn}^{2+}$ [85], as proved by XPS in Figure S7. However this $\mathrm{Zn}$ could be bonded within the zeolite framework, bonded to an hydroxyl group or chlorinated when using $\mathrm{ZnCl}_{2}$ as modifier $[38,86]$. In fact, we searched for Zn-chlorinated species using XPS and electrondispersive $\mathrm{x}$-ray spectroscopy and we did not find any evidence of $\mathrm{Cl}$ in our $\mathrm{ZnZ5}$ zeolite. Mehdad et al. [75] found that $\mathrm{ZnOH}^{+}$cations exhibited a FTIR band at $3665 \mathrm{~cm}^{-1}$, 
however, we did not observe this band in the FTIR spectra of our ZnZ5 zeolite (Figure 2a). Thus, the most probable state of $\mathrm{Zn}$ is the one proposed by El-Malki et al. [84]: $\mathrm{Zn}^{+}$ - OSi interacting with one zeolite framework, in concordance with our NMR and FTIR results (Figures $2 \mathrm{~b}$ and $3 \mathrm{a}$ ). On the other hand, these species can react with water in the following reverse reaction:

$$
\text { (ZO) }-\mathrm{Zn}^{+}-\mathrm{OSi}+\mathrm{H}_{2} \mathrm{O} \leftrightarrow(\mathrm{ZO})-\mathrm{ZnOH}++\mathrm{Si}-\mathrm{OH}
$$

Where ( $\mathrm{ZO})$ is an oxygen bridging one $\mathrm{Al}$ and one $\mathrm{Si}$ atoms in the zeolite structure. Above all, the modification with $\mathrm{Zn}$ drastically decreases the overall activity by having lower concentration of acid sites. This catalyst has a higher concentration less methylated hydrocarbon pool species (Figure 7b) which would mean a higher activity. Nonetheless, the scarce Brønsted acid sites limit the methylation-dealkylation reactions of hydrocarbon pool species, but more importantly their degradation (particularly hexaMB, Figure 7c) into coke. This effect has a direct result by lowering the propagation of the aromatic cycle in favor of the olefinic one and therefore increasing the selectivity of propylene over ethylene (Figure 5). Another positive outcome of the $\mathrm{Zn}$ modification is that hydrogen transfer reaction, that normally is associated with strong Brønsted acidity, is lowered resulting in the selectivity decrease of less interesting products such as paraffins and aromatics (Figure 5). This result concords with that obtained by Bi et al. [38] when using $\mathrm{ZnCl}_{2}$ as a modifier. They reasoned their observations of the poor MTA reaction performance on the $\mathrm{ZnCl}_{2}$ modified catalysts in terms of the reduced amount of mediumstrength BAS, which disfavors light olefins cyclization and hydrogen transfer reactions. Thus, the particular effect of lower aromatic selectivity for the $\mathrm{ZnCl}_{2}$ modified zeolite should be framed based on the severe depletion of the strong and Brønsted acid sites.

The operando FTIR spectroscopy experiments gave us additional information about the role of different active sites. We inspected the $\mathrm{OH}$ stretching vibration region after the MTO reaction (Figure S8) and we observed the consumption of different sites of the zeolite phase and alumina phase. By contrasting with our Py-FTIR measurements (Figure $3 \mathrm{~b}$ and $\mathrm{S} 2$ ), we verified the consumption of bridged $\mathrm{OH}$ groups (strong BAS) in all the catalyst and $\mathrm{P}-\mathrm{OH}$ groups (medium-strength BAS) by chemisorption of carbocationic intermediates. The consumption of the rest of the sites identified should take place by physisorption of products and/or intermediates taking a proton off from $\mathrm{Si}-\mathrm{OH}$ or $\mathrm{Al}-\mathrm{OH}$ groups.

Most of the kinetic observations obtained in fixed-bed and operando reactors reveal a sigmoidal function that is typical of autocatalytic reactions [61]. In an ideal autocatalytic reaction, the representation of the reaction rate against the concentration or time describes a parabola indicating that the process reaches a maximum rate $\left(r_{m}\right)$ and this happens for 
a concentration measured at a certain time $\left(t_{m}\right)$. Herein, we consider $r_{m}$ and $t_{m}$ as kinetic parameters of the MTO reaction expressing how long $\left(t_{m}\right)$ a specific MTO reaction event takes to reach its maximum level of activity $\left(r_{m}\right)$. The comparison of these parameters among the different catalysts tested helps us to analyze the kinetic effect of the $\mathrm{P}$ and $\mathrm{Zn}$ modifications. Figure S9 exemplifies a typical calculation of these parameters. In general, we fitted the experimental data to sigmoidal functions $f(t)$ and calculated their derivative for a range of $t$ values in order to find the $t_{m}$ value at which the derivative is maximum, that is, $r_{m}=d f /\left.d t\right|_{t=t_{m}}$.

Figure 12 depicts the $t_{m}$ increment and $r_{m}$ decrement of the modified-zeolite catalysts compared with the control-parent catalyst for the following kinetic steps: Figure 4a, conversion vs. W/F; Figure 4b, conversion vs. n Figure $6 \mathrm{~b}$, coke formation on the acid sites in the poisoning stage $\left(\mathrm{C}_{1}\right)$ vs. TOS; Figure $6 \mathrm{~b}$, coke deposited on the matrix in the pore blockage stage $\left(\mathrm{C}_{2}\right)$ vs. TOS; Figure 9, the FTIR band at $1481 \mathrm{~cm}^{-1}$ vs. TOS; Figure 9, the FTIR band at $1570 \mathrm{~cm}^{-1}$ vs. TOS; Figure 11, the UV-vis-NIR band at $412 \mathrm{~nm}$ vs. TOS; Figure 11, the UV-vis-NIR band at $706 \mathrm{~nm}$ vs. TOS. The increment of $t_{m}$ is detrimental for the catalyst as it requires more time to overpass the induction period. Nevertheless, this induction period is not significant for the industrial implementation of MTO process as the reactor works with relatively high pressures of methanol and excess of catalyst [12]. In fact, the differences in the values of $t_{m}$ increments observed in Figure 12 depends on the reactor setup used (fixed-bed, FTIR operando or UV-vis-NIR operando reactors), i.e. methanol partial pressure, catalyst contact, etc. The exception to the detrimental effect of $t_{m}$ is the X vs. TOS scenario (in grey background), which is directly linked with the increment of catalytic lifetime. That is, ZnZ5 catalyst has $80 \%$ more lifetime than its counterparts.

Figure 11.

Figure 12 also shows the $r_{m}$ decrement caused by the modifications. The evolutions of $\mathrm{X}$ vs. $\mathrm{W} / \mathrm{F}$ and particularly vs. $\mathrm{n}_{\mathrm{BAS}} / \mathrm{F}$ indicate the slower rate of oxygenates transformation (between -24\% and -38\%) using ZnZ5 catalyst, which is linked to the slower formation of hydrocarbon pool species on the catalyst (evolutions of $1570 \mathrm{~cm}^{-1}$ and $412 \mathrm{~nm}$ vs. TOS, in dashed grey background). On the contrary, the slower formation of coke (scenarios $\mathrm{C}_{1}$ and $\mathrm{C}_{2}$, in grey background) between $-28 \%$ and $-42 \%$, also supported by operando reactor results (evolutions of $1481 \mathrm{~cm}^{-1}$ and $706 \mathrm{~nm}$ vs. TOS, in grey background), indicates the much slower deactivation of ZnZ5 catalyst. The PZ5 catalyst has relatively similar kinetic and deactivation behavior to that of the HZ5 catalyst and does not offer significant advances. The ZnZ5 catalyst, however, shows very promising outcomes of higher propylene selectivity and slower coke formation at the expense of requiring greater amount of material in order to reach comparable conversion of oxygenates. 
The kinetic information aforementioned invites to present the maximum rate obtained for some important kinetic events during the MTO reaction in order to reinforce the effect of the modifiers. For this, we consider the events related with the formation of trapped species (coke and hydrocarbon pool species) measurable in each system: coke content $\left(C_{C}\right)$ vs. TOS from Figure 6 b, the $1570 \mathrm{~cm}^{-1}$ band vs. TOS from Figure 9, and the $412 \mathrm{~nm}$ band vs. TOS from Figure 11. Additionally, initial kinetics given by the conversion (X) vs. space time (W/F) is also analyzed. Table 4 summarizes the results obtained, indicating the maximum empirical rate obtained for each event. As seen, the maximum rate for the formation of trapped species have similar magnitude order for all the kinetic events. The HZ5 and PZ5 catalysts have relatively similar values, being slightly lower for the latter catalyst. The ZnZ5 catalyst show a completely different behavior with lower rates but specially in terms of coke formation. This confirms the effect of the modifications as responsible for final MTO performance. Additionally, we calculated the turnover frequencies (TOF) and turnover numbers (TON) based on the kinetic information obtained in the fixed-bed reactor and the $\mathrm{n}_{\mathrm{BAS}}$ for each catalyst. We considered the experiments that gave similar initial conversion (Figures 4 and $6 \mathrm{~b}$ ) for the calculations:

$$
T O F=\frac{r_{m}}{n_{B A S}}
$$

where $r_{m}$ is the maximum rate and $\mathrm{n}_{\mathrm{BAS}}$ is the number of BAS. The TON was calculated using the corresponding catalyst lifetimes up to $10 \%$ conversions $\left(\operatorname{TOS}_{\mathrm{X}}=0.1\right)$ determined from Figure 6b:

$$
T O N=T O F \cdot T O S_{X=0.1}
$$

Table 4 also summarizes the results of TOF and TON obtained for each catalyst. As seen, the HZ5 and PZ5 catalysts have similar TOF, slightly higher for the latter catalyst, whereas the ZnZ5 catalyst has the lowest TOF. Despite this, the number of oxygenates converted per active site (BAS) is significantly higher for ZnZ5 catalyst (27\% increase), confirming its improved coke resistance for undergoing deactivation.

Table 4. Empirical maximum rates for various kinetic events during the MTO reaction over the HZ5, PZ5 and ZnZ5 catalysts.

\begin{tabular}{|l|l|l|l|}
\hline & $\mathrm{HZ5}$ & PZ5 & ZnZ5 \\
\hline C $_{\text {C vs. TOS, } \mathrm{r}_{\mathrm{m}}\left(10^{-4} \mathrm{mg} \mathrm{g}^{-1} \mathrm{~s}^{-1}\right)}$ & 9.6 & 9.3 & 5.6 \\
\hline $1570 \mathrm{~cm}^{-1}$ vs. TOS, $\mathrm{r}_{\mathrm{m}}\left(10^{-4}\right.$ a.u. $\left.\mathrm{g}^{-1} \mathrm{~s}^{-1}\right)$ & 1.6 & 1.4 & 1.2 \\
\hline $412 \mathrm{~nm}$ vs. TOS, $\mathrm{r}_{\mathrm{m}}\left(10^{-3}\right.$ a.u. $\left.\mathrm{g}^{-1} \mathrm{~s}^{-1}\right)$ & 1.8 & 1.3 & 0.97 \\
\hline X vs. W/F, $\mathrm{r}_{\mathrm{m}}\left(10^{-3} \mathrm{~mol} \mathrm{~g} \mathrm{~s}^{-1}\right)$ & 1.1 & 1.0 & 0.65 \\
\hline TOF $\left(\mathrm{mol} \mathrm{mol} \mathrm{s}^{-1}\right)$ & 9.8 & 9.5 & 7.6 \\
\hline TON $\left(10^{3} \mathrm{~mol} \mathrm{~mol}^{-1}\right)$ & 381 & 381 & 483 \\
\hline
\end{tabular}




\section{CONCLUSIONS}

We have modified the properties of the H-ZSM-5 catalyst by using $\mathrm{H}_{3} \mathrm{PO}_{4}$ or $\mathrm{ZnCl}_{2}$ trying to reach similar ratios of $\mathrm{P} / \mathrm{Al}$ or $\mathrm{Zn} / \mathrm{Al}$. The characterization results show that $\mathrm{H}_{3} \mathrm{PO}_{4}$ alters mildly the acid sites by desilicating silanol groups and dealuminating part of the framework Al. The $\mathrm{ZnCl}_{2}$ exchanges $\mathrm{NH}_{4}{ }^{+}$cations in Brønsted acid sites with $\mathrm{Zn}$ species acting as Lewis acid sites and this causes the decrease of Brønsted ones. Those changes are accompanied by a shift of the acidity toward the intersection of the micropores.

The combined results of fixed-bed (at similar conversion levels), FTIR and UV-vis operando reactors during the methanol-to-olefin reaction lead to conclude that the catalyst modified with $\mathrm{P}$ has slightly slower steps of induction, autocatalysis and deactivation, but at mechanistic level the reaction is the same. On the contrary, Zn modified zeolite leads to the preferential slowdown of the aromatic cycle (by forming mainly hexamethylbenzene), higher predominance of the olefinic cycle, slower hydrogen transfer reactions and slower degradations of the aromatic species. As a result, we observe an improvement of propylene selectivity, catalyst lifetime and coke formation drop when using the ZnZ5 catalyst at the same initial oxygenates (methanol and dimethyl ether) conversion.

Finally, we determined the relationship between the reaction and deactivation mechanisms from the results of evolution with time on stream of the conversion, coke content and reaction intermediates. The interpretation of results concords with the dualcycle mechanism extensively proposed in the literature, and we found that the aromatic cycle and hydrogen transfer reactions have a key role on catalyst deactivation.

\section{ACKNOWLEDGMENTS}

This work was possible thanks to the financial support of the Ministry of Economy, Industry and Competitiveness of the Spanish Government (Project CTQ2016-79646-P, co-founded with ERDF funds) and the Basque Government (Project IT748-13, IT91216). J.V. is thankful for his fellowship granted by the Ministry of Economy, Industry and Competitiveness of the Spanish Government (BES-2014-069980). The authors are thankful for technical and human support provided by IZO-SGI SGIker of UPV/EHU and European funding (ERDF and ESF).

\section{REFERENCES}

[1] C.D. Chang, A.J. Silvestri, The conversion of methanol and other O-compounds to hydrocarbons over zeolite catalysts, J. Catal. 47 (1977) 249-259. doi:10.1016/0021-9517(79)90103-9. 
[2] S.L. Meisel, J.P. McCullough, C.H. Lechthaler, P.B. Weisz, Gasoline from methanol in one step, Chem. Tech. 6 (1976) 86-89.

[3] J.M. Bermudez, B. Fidalgo, Production of bio-syngas and bio-hydrogen via gasification, in: Handb. Biofuels Prod., Elsevier, 2016: pp. 431-494. doi:10.1016/B978-0-08-100455-5.00015-1.

[4] P.A. Alaba, A. Abbas, W.M.W. Daud, Insight into catalytic reduction of $\mathrm{CO}_{2}$ : Catalysis and reactor design, J. Clean. Prod. 140 (2017) 1298-1312. doi:10.1016/j.jclepro.2016.10.022.

[5] M. Stöcker, Methanol-to-hydrocarbons: catalytic materials and their behavior, Microporous Mesoporous Mater. 29 (1999) 3-48. doi:10.1016/S13871811(98)00319-9.

[6] S. Ilias, A. Bhan, Mechanism of the catalytic conversion of methanol to hydrocarbons, ACS Catal. 3 (2013) 18-31. doi:10.1021/cs3006583.

[7] U. Olsbye, S. Svelle, M. Bjrgen, P. Beato, T.V.W.W. Janssens, F. Joensen, S. Bordiga, K.P. Lillerud, Conversion of methanol to hydrocarbons: How zeolite cavity and pore size controls product selectivity, Angew. Chemie - Int. Ed. 51 (2012) 5810-5831. doi:10.1002/anie.201103657.

[8] U. Olsbye, M. Bjørgen, S. Svelle, K.P. Lillerud, S. Kolboe, Mechanistic insight into the methanol-to-hydrocarbons reaction, Catal. Today. 106 (2005) 108-111. doi:10.1016/j.cattod.2005.07.135.

[9] M. Bjørgen, S. Svelle, F. Joensen, J. Nerlov, S. Kolboe, F. Bonino, L. Palumbo, S. Bordiga, U. Olsbye, Conversion of methanol to hydrocarbons over zeolite HZSM-5: On the origin of the olefinic species, J. Catal. 249 (2007) 195-207. doi:10.1016/j.jcat.2007.04.006.

[10] G. Seo, J.H. Kim, H.G. Jang, Methanol-to-olefin conversion over zeolite catalysts: Active intermediates and deactivation, Catal. Surv. from Asia. 17 (2013) 103-118. doi:10.1007/s10563-013-9157-4.

[11] U. Olsbye, S. Svelle, K.P. Lillerud, Z.H. Wei, Y.Y. Chen, J.F. Li, J.G. Wang, W.B. Fan, The formation and degradation of active species during methanol conversion over protonated zeotype catalysts, Chem. Soc. Rev. 44 (2015) 71557176. doi:10.1039/C5CS00304K.

[12] P. Tian, Y. Wei, M. Ye, Z. Liu, Methanol to olefins (MTO): From fundamentals to commercialization, ACS Catal. 5 (2015) 1922-1938. doi:10.1021/acscatal.5b00007.

[13] E. Epelde, M. Ibáñez, A.T. Aguayo, A.G. Gayubo, J. Bilbao, P. Castaño, Differences among the deactivation pathway of HZSM-5 zeolite and SAPO-34 in the transformation of ethylene or 1-butene to propylene, Microporous Mesoporous Mater. 195 (2014) 284-293. doi:10.1016/j.micromeso.2014.04.040.

[14] A.D. Chowdhury, A.L. Paioni, K. Houben, G.T. Whiting, M. Baldus, B.M. Weckhuysen, Bridging the gap between the direct and hydrocarbon pool mechanisms of the methanol-to-hydrocarbons process, Angew. Chemie - Int. Ed. 57 (2018) 8095-8099. doi:10.1002/anie.201803279.

[15] L. Qi, Y. Wei, L. Xu, Z. Liu, Reaction behaviors and kinetics during induction period of methanol conversion on HZSM-5 zeolite, ACS Catal. 5 (2015) 39733982. doi:10.1021/acscatal.5b00654. 
[16] C. Wang, J. Xu, G. Qi, Y. Gong, W. Wang, P. Gao, Q. Wang, N. Feng, X. Liu, F. Deng, Methylbenzene hydrocarbon pool in methanol-to-olefins conversion over zeolite H-ZSM-5, J. Catal. 332 (2015) 127-137. doi:10.1016/j.jcat.2015.10.001.

[17] S. Ilias, A. Bhan, The mechanism of aromatic dealkylation in methanol-tohydrocarbons conversion on H-ZSM-5: What are the aromatic precursors to light olefins?, J. Catal. 311 (2014) 6-16. doi:10.1016/j.jcat.2013.11.003.

[18] C. Wang, Y. Chu, A. Zheng, J. Xu, Q. Wang, P. Gao, G. Qi, Y. Gong, F. Deng, New insight into the hydrocarbon-pool chemistry of the methanol-to-olefins conversion over zeolite H-ZSM-5 from GC-MS, solid-state NMR spectroscopy, and DFT calculations, Chem. - A Eur. J. 20 (2014) 12432-12443. doi:10.1002/chem.201403972.

[19] M. Bjørgen, U. Olsbye, S. Kolboe, Coke precursor formation and zeolite deactivation: Mechanistic insights from hexamethylbenzene conversion, J. Catal. 215 (2003). doi:10.1016/S0021-9517(02)00050-7.

[20] S. Müller, Y. Liu, M. Vishnuvarthan, X. Sun, A.C. Van Veen, G.L. Haller, M. Sanchez-Sanchez, J.A. Lercher, Coke formation and deactivation pathways on HZSM-5 in the conversion of methanol to olefins, J. Catal. 325 (2015) 48-59. doi:10.1016/j.jcat.2015.02.013.

[21] M. Argyle, C. Bartholomew, Heterogeneous catalyst deactivation and regeneration: A review, Catalysts. 5 (2015) 145-269. doi:10.3390/catal5010145.

[22] X. Sun, S. Mueller, Y. Liu, H. Shi, G.L. Haller, M. Sanchez-Sanchez, A.C. Van Veen, J.A. Lercher, On reaction pathways in the conversion of methanol to hydrocarbons on HZSM-5, J. Catal. 317 (2014) 185-197. doi:10.1016/j.jcat.2014.06.017.

[23] Z. Liu, X. Dong, X. Liu, Y. Han, Oxygen-containing coke species in zeolitecatalyzed conversion of methanol to hydrocarbons, Catal. Sci. Technol. 6 (2016) 8157-8165. doi:10.1039/C6CY01463A.

[24] Z. Liu, X. Dong, Y. Zhu, A.H. Emwas, D. Zhang, Q. Tian, Y. Han, Investigating the influence of mesoporosity in zeolite Beta on its catalytic performance for the conversion of methanol to hydrocarbons, ACS Catal. 5 (2015) 5837-5845. doi:10.1021/acscatal.5b01350.

[25] H.E.H.E. van der Bij, B.M.B.M. Weckhuysen, Phosphorus promotion and poisoning in zeolite-based materials: synthesis, characterisation and catalysis, Chem. Soc. Rev. 44 (2015) 7406-7428. doi:10.1039/C5CS00109A.

[26] M. Kaarsholm, F. Joensen, J. Nerlov, R. Cenni, J. Chaouki, G.S. Patience, Phosphorous modified ZSM-5: Deactivation and product distribution for MTO, Chem. Eng. Sci. 62 (2007) 5527-5532. doi:10.1016/j.ces.2006.12.076.

[27] D. Van Vu, Y. Hirota, N. Nishiyama, Y. Egashira, K. Ueyama, High propylene selectivity in methanol-to-olefn reaction over H-ZSM-5 catalyst treated with phosphoric acid, J. Japan Pet. Inst. 53 (2010) 232-238. doi:10.1627/jpi.53.232.

[28] M. Derewinski, P. Sarv, X. Sun, S. Müller, A.C. Van Veen, J.A. Lercher, Reversibility of the modification of HZSM-5 with phosphate anions, J. Phys. Chem. C. 118 (2014) 6122-6131. doi:10.1021/jp4053677.

[29] P. Losch, G. Laugel, J.S. Martinez-Espin, S. Chavan, U. Olsbye, B. Louis, Phosphorous modified ZSM-5 zeolites: Impact on methanol conversion into 
olefins, Top. Catal. 58 (2015) 826-832. doi:10.1007/s11244-015-0449-y.

[30] H.G. Jang, H.K. Min, S.B. Hong, G. Seo, Tetramethylbenzenium radical cations as major active intermediates of methanol-to-olefin conversions over phosphorous-modified HZSM-5 zeolites, J. Catal. 299 (2013) 240-248. doi:10.1016/j.jcat.2012.12.014.

[31] E. Epelde, J.I. Santos, P. Florian, A.T. Aguayo, A.G. Gayubo, J. Bilbao, P. Castaño, Controlling coke deactivation and cracking selectivity of MFI zeolite by $\mathrm{H}_{3} \mathrm{PO}_{4}$ or KOH modification, Appl. Catal. A Gen. 505 (2015) 105-115. doi:10.1016/j.apcata.2015.07.022.

[32] H.E. Van Der Bij, B.M. Weckhuysen, Local silico-aluminophosphate interfaces within phosphated H-ZSM-5 zeolites, Phys. Chem. Chem. Phys. 16 (2014) 98929903. doi:10.1039/c3cp54791d.

[33] H.E. Van Der Bij, L.R. Aramburo, B. Arstad, J.J. Dynes, J. Wang, B.M. Weckhuysen, Phosphatation of zeolite H-ZSM-5: A combined microscopy and spectroscopy study, ChemPhysChem. 15 (2014) 283-292. doi:10.1002/cphc.201300910.

[34] T. Blasco, A. Corma, J. Martínez-Triguero, Hydrothermal stabilization of ZSM-5 catalytic-cracking additives by phosphorus addition, J. Catal. 237 (2006) 267277. doi:10.1016/j.jcat.2005.11.011.

[35] Z. Wei, L. Chen, Q. Cao, Z. Wen, Z. Zhou, Y. Xu, X. Zhu, Steamed Zn/ZSM-5 catalysts for improved methanol aromatization with high stability, Fuel Process. Technol. 162 (2017) 66-77. doi:10.1016/j.fuproc.2017.03.026.

[36] X. Niu, J. Gao, Q. Miao, M. Dong, G. Wang, W. Fan, Z. Qin, J. Wang, Influence of preparation method on the performance of Zn-containing HZSM-5 catalysts in methanol-to-aromatics, Microporous Mesoporous Mater. 197 (2014) 252-261. doi:10.1016/j.micromeso.2014.06.027.

[37] Y. Ono, H. Adachi, Y. Senoda, Selective conversion of methanol into aromatic hydrocarbons over zinc-exchanged ZSM-5 zeolites, J. Chem. Soc. Faraday Trans. 1 Phys. Chem. Condens. Phases. 84 (1988) 1091-1099. doi:10.1039/F19888401091.

[38] Y. Bi, Y. Wang, X. Chen, Z. Yu, L. Xu, Methanol aromatization over HZSM-5 catalysts modified with different zinc salts, Chinese J. Catal. 35 (2014) 17401751. doi:10.1016/S1872-2067(14)60145-5.

[39] Y. Jia, J. Wang, K. Zhang, S. Liu, G. Chen, Y. Yang, C. Ding, P. Liu, Catalytic conversion of methanol to aromatics over nano-sized HZSM-5 zeolite modified by $\mathrm{ZnSiF}_{6} \cdot 6 \mathrm{H}_{2} \mathrm{O}$, Catal. Sci. Technol. 7 (2017) 1776-1791. doi:10.1039/C7CY00143F.

[40] I. Pinilla-Herrero, E. Borfecchia, J. Holzinger, U. V. Mentzel, F. Joensen, K.A. Lomachenko, S. Bordiga, C. Lamberti, G. Berlier, U. Olsbye, S. Svelle, J. Skibsted, P. Beato, High Zn/Al ratios enhance dehydrogenation vs hydrogen transfer reactions of Zn-ZSM-5 catalytic systems in methanol conversion to aromatics, J. Catal. 362 (2018) 146-163. doi:10.1016/j.jcat.2018.03.032.

[41] T. Gong, L. Qin, J. Lu, H. Feng, ZnO modified ZSM-5 and y zeolites fabricated by atomic layer deposition for propane conversion, Phys. Chem. Chem. Phys. 18 (2016) 601-614. doi:10.1039/c5cp05043j. 
[42] I.I. Ivanova, Y.G. Kolyagin, Impact of in situ MAS NMR techniques to the understanding of the mechanisms of zeolite catalyzed reactions., Chem. Soc. Rev. 39 (2010) 5018-5050. doi:10.1039/c0cs00011f.

[43] S.-H. Zhang, Z.-X. Gao, S.-J. Qing, S.-Y. Liu, Y. Qiao, Effect of zinc introduction on catalytic performance of ZSM-5 in conversion of methanol to light olefins, Chem. Pap. 68 (2014) 1-7. doi:10.2478/s11696-014-0536-8.

[44] I. Yarulina, S. Bailleul, A. Pustovarenko, J.R. Martinez, K. De Wispelaere, J. Hajek, B.M. Weckhuysen, K. Houben, M. Baldus, V. Van Speybroeck, F. Kapteijn, J. Gascon, Suppression of the aromatic cycle in methanol-to-olefins reaction over ZSM-5 by post-synthetic modification using calcium, ChemCatChem. 8 (2016) 3005-3005. doi:10.1002/cctc.201601164.

[45] I.A. Bakare, O. Muraza, M. Yoshioka, Z.H. Yamani, T. Yokoi, Conversion of methanol to olefins over Al-rich ZSM-5 modified with alkaline earth metal oxides, Catal. Sci. Technol. 6 (2016) 7852-7859. doi:10.1039/C6CY00867D.

[46] I. Yarulina, A.D. Chowdhury, F. Meirer, B.M. Weckhuysen, J. Gascon, Recent trends and fundamental insights in the methanol-to-hydrocarbons process, Nat. Catal. 1 (2018) 398-411. doi:10.1038/s41929-018-0078-5.

[47] I. Yarulina, K. De Wispelaere, S. Bailleul, J. Goetze, M. Radersma, E. AbouHamad, I. Vollmer, M. Goesten, B. Mezari, E.J.M. Hensen, J.S. Martínez-Espín, M. Morten, S. Mitchell, J. Perez-Ramirez, U. Olsbye, B.M. Weckhuysen, V. Van Speybroeck, F. Kapteijn, J. Gascon, Structure-performance descriptors and the role of Lewis acidity in the methanol-to-propylene process, Nat. Chem. DOI:10.103 (2018). doi:10.1038/s41557-018-0081-0.

[48] P. Castaño, J. Ruiz-Martínez, E. Epelde, A.G. Gayubo, B.M. Weckhuysen, Spatial distribution of zeolite ZSM-5 within catalyst bodies affects selectivity and stability of methanol-to-hydrocarbons conversion, ChemCatChem. 5 (2013) 2827-2831. doi:10.1002/cctc.201300218.

[49] P. Pérez-Uriarte, M. Gamero, A. Ateka, M. Díaz, A.T. Aguayo, J. Bilbao, Effect of the acidity of HZSM-5 zeolite and the binder in the DME transformation to olefins, Ind. Eng. Chem. Res. 55 (2016) 1513-1521. doi:10.1021/acs.iecr.5b04477.

[50] P. Magnoux, P. Roger, C. Canaff, V. Fouche, N.S. Gnep, M. Guisnet, New technique for the characterization of carbonaceous compounds responsible for zeolite deactivation, in: Stud. Surf. Sci. Catal., 1987: pp. 317-330. doi:10.1016/S0167-2991(09)60370-0.

[51] Y. Ji, H. Yang, Q. Zhang, W. Yan, Phosphorus modification increases catalytic activity and stability of ZSM-5 zeolite on supercritical catalytic cracking of ndodecane, J. Solid State Chem. 251 (2017). doi:10.1016/j.jssc.2017.03.023.

[52] T. Yokoi, H. Mochizuki, S. Namba, J.N. Kondo, T. Tatsumi, Control of the Al distribution in the framework of ZSM-5 zeolite and its evaluation by solid-state NMR technique and catalytic properties, J. Phys. Chem. C. 119 (2015) 1530315315. doi:10.1021/acs.jpcc.5b03289.

[53] T. Liang, J. Chen, Z. Qin, J. Li, P. Wang, S. Wang, G. Wang, M. Dong, W. Fan, J. Wang, Conversion of methanol to olefins over H-ZSM-5 zeolite: Reaction pathway is related to the framework aluminum siting, ACS Catal. 6 (2016) 7311- 
7325. doi:10.1021/acscatal.6b01771.

[54] S. Sklenak, J. Dedecek, C. Li, B. Wichterlová, V. Gábová, M. Sierka, J. Sauer, Aluminium siting in the ZSM-5 framework by combination of high resolution ${ }^{27}$ Al NMR and DFT/MM calculations., Phys. Chem. Chem. Phys. 11 (2009) 1237-1247. doi:10.1039/b807755j.

[55] M. Ibáñez, E. Epelde, A.T. Aguayo, A.G. Gayubo, J. Bilbao, P. Castaño, Selective dealumination of HZSM-5 zeolite boosts propylene by modifying 1butene cracking pathway, Appl. Catal. A Gen. 543 (2017) 1-9. doi:10.1016/j.apcata.2017.06.008.

[56] E.-M. El-Malki, R.A. van Santen, W.M.H. Sachtler, Introduction of Zn, Ga, and Fe into HZSM-5 cavities by sublimation: Identification of acid sites, J. Phys. Chem. B. 103 (1999) 4611-4622. doi:10.1021/jp9901161.

[57] M. Göhlich, W. Reschetilowski, S. Paasch, Spectroscopic study of phosphorus modified H-ZSM-5, Microporous Mesoporous Mater. 142 (2011) 178-183. doi:10.1016/j.micromeso.2010.11.033.

[58] M.L. Gou, R. Wang, Q. Qiao, X. Yang, Effect of mesoporosity by desilication on acidity and performance of HZSM-5 in the isomerization of styrene oxide to phenylacetaldehyde, Microporous Mesoporous Mater. 206 (2015) 170-176. doi:10.1016/j.micromeso.2014.12.006.

[59] S.M.T. Almutairi, B. Mezari, P.C.M.M. Magusin, E.A. Pidko, E.J.M. Hensen, Structure and reactivity of Zn-modified ZSM-5 zeolites: The importance of clustered cationic Zn complexes, ACS Catal. 2 (2012) 71-83. doi:10.1021/cs200441e.

[60] A.T. Aguayo, D. Mier, A.G. Gayubo, M. Gamero, J. Bilbao, Kinetics of methanol transformation into hydrocarbons on a HZSM-5 zeolite catalyst at high temperature (400-550 $\left.{ }^{\circ} \mathrm{C}\right)$, Ind. Eng. Chem. Res. 49 (2010) 12371-12378. doi:10.1021/ie101047f.

[61] A.J. Bissette, S.P. Fletcher, Mechanisms of autocatalysis, Angew. Chemie - Int. Ed. 52 (2013) 12800-12826. doi:10.1002/anie.201303822.

[62] M. Dusselier, M.A. Deimund, J.E. Schmidt, M.E. Davis, Methanol-to-olefins catalysis with hydrothermally treated zeolite SSZ-39, ACS Catal. 5 (2015) 60786085. doi:10.1021/acscatal.5b01577.

[63] S. Ilias, R. Khare, A. Malek, A. Bhan, A descriptor for the relative propagation of the aromatic- and olefin-based cycles in methanol-to-hydrocarbons conversion on H-ZSM-5, J. Catal. 303 (2013) 135-140. doi:10.1016/j.jcat.2013.03.021.

[64] A. Devaraj, M. Vijayakumar, J. Bao, M.F. Guo, M.A. Derewinski, Z. Xu, M.J. Gray, S. Prodinger, K.K. Ramasamy, Discerning the location and nature of coke deposition from surface to bulk of spent zeolite catalysts, Sci. Rep. 6 (2016). doi:10.1038/srep37586.

[65] D. Mores, E. Stavitski, M.H.F. Kox, J. Kornatowski, U. Olsbye, B.M. Weckhuysen, Space- and time-resolved in-situ spectroscopy on the coke formation in molecular sieves: Methanol-to-olefin conversion over H-ZSM-5 and H-SAPO-34, Chem. - A Eur. J. 14 (2008) 11320-11327. doi:10.1002/chem.200801293.

[66] D. Mores, J. Kornatowski, U. Olsbye, B.M. Weckhuysen, Coke formation during 
the methanol-to-olefin conversion: In situ microspectroscopy on individual HZSM-5 crystals with different brønsted acidity, Chem. - A Eur. J. 17 (2011) 2874-2884. doi:10.1002/chem.201002624.

[67] F.L. Bleken, T.V.W. Janssens, S. Svelle, U. Olsbye, Product yield in methanol conversion over ZSM-5 is predominantly independent of coke content, Microporous Mesoporous Mater. 164 (2012) 190-198. doi:10.1016/j.micromeso.2012.06.020.

[68] M. Bjørgen, F. Joensen, K.P. Lillerud, U. Olsbye, S. Svelle, The mechanisms of ethene and propene formation from methanol over high silica H-ZSM-5 and Hbeta, Catal. Today. 142 (2009) 90-97. doi:10.1016/j.cattod.2009.01.015.

[69] Q. Qian, J. Ruiz-Martínez, M. Mokhtar, A.M. Asiri, S.A. Al-Thabaiti, S.N. Basahel, B.M. Weckhuysen, Single-catalyst particle spectroscopy of alcohol-toolefins conversions: Comparison between SAPO-34 and SSZ-13, Catal. Today. 226 (2014) 14-24. doi:10.1016/j.cattod.2013.09.056.

[70] H.G. Jang, H.K. Min, J.K. Lee, S.B. Hong, G. Seo, SAPO-34 and ZSM-5 nanocrystals' size effects on their catalysis of methanol-to-olefin reactions, Appl. Catal. A Gen. 437-438 (2012) 120-130. doi:10.1016/j.apcata.2012.06.023.

[71] J.W. Park, G. Seo, IR study on methanol-to-olefin reaction over zeolites with different pore structures and acidities, Appl. Catal. A Gen. 356 (2009) 180-188. doi:10.1016/j.apcata.2009.01.001.

[72] M. Trombetta, A.G. Alejandre, J.R. Solis, G. Busca, An FT-IR study of the reactivity of hydrocarbons on the acid sites of HZSM5 zeolite, Appl. Catal., A. 198 (2000) 81-93. doi:10.1016/S0926-860X(99)00497-4.

[73] Saepurahman, M. Visur, U. Olsbye, M. Bjørgen, S. Svelle, In situ FT-IR mechanistic investigations of the zeolite catalyzed methylation of benzene with methanol: H-ZSM-5 versus H-beta, Top. Catal. 54 (2011) 1293-1301. doi:10.1007/s11244-011-9751-5.

[74] W. Dai, G. Wu, L. Li, N. Guan, M. Hunger, Mechanisms of the deactivation of SAPO-34 materials with different crystal sizes applied as MTO catalysts, ACS Catal. 3 (2013) 588-596. doi:10.1021/cs400007v.

[75] A. Mehdad, N. Gould, B. Xu, R. Lobo, Effect of steam and $\mathrm{CO}_{2}$ in ethane activation on Zn-ZSM-5, Catal. Sci. Technol. 8 (2017) 358-366. doi:10.1039/C7CY01850A.

[76] C.W. Bauschlicher, E. Peeters, L.J. Allamandola, The infrared spectra of very large irregular polycyclic aromatic hydrocarbons (PAHs): Observational probes of astronomical PAH geometry, size, and charge, Astrophys. J. 697 (2009) 311327. doi:10.1088/0004-637X/697/1/311.

[77] K. Hemelsoet, Q. Qian, T. De Meyer, K. De Wispelaere, B. De Sterck, B.M. Weckhuysen, M. Waroquier, V. Van Speybroeck, Identification of intermediates in zeolite-catalyzed reactions by in situ UV/Vis microspectroscopy and a complementary set of molecular simulations, Chem. - A Eur. J. 19 (2013) 1659516606. doi:10.1002/chem.201301965.

[78] Q. Qian, J. Ruiz-Martínez, M. Mokhtar, A.M. Asiri, S.A. Al-Thabaiti, S.N. Basahel, H.E. van der Bij, J. Kornatowski, B.M. Weckhuysen, Single-particle spectroscopy on large SAPO-34 crystals at work: Methanol-to-olefin versus 
ethanol-to-olefin processes, Chem. - A Eur. J. 19 (2013) 11204-11215.

doi:10.1002/chem.201300540.

[79] E. Borodina, F. Meirer, I. Lezcano-González, M. Mokhtar, A.M. Asiri, S.A. AlThabaiti, S.N. Basahel, J. Ruiz-Martinez, B.M. Weckhuysen, Influence of the reaction temperature on the nature of the active and deactivating species during methanol to olefins conversion over H-SSZ-13, ACS Catal. 5 (2015) 992-1003. doi:10.1021/cs501345g.

[80] J. Goetze, B.M. Weckhuysen, Spatiotemporal coke formation over zeolite ZSM-5 during the methanol-to-olefins process as studied with operando UV-vis spectroscopy: a comparison between H-ZSM-5 and Mg-ZSM-5, Catal. Sci. Technol. 8 (2018) 1632-1644. doi:10.1039/C7CY02459B.

[81] V.I. Yakerson, T. V. Vasina, L.I. Lafer, V.P. Sytnyk, G.L. Dykh, A. V. Mokhov, O. V. Bragin, K.M. Minachev, The properties of zinc and gallium containing pentasils - The catalysts for the aromatization of lower alkanes, Catal. Letters. 3 (1989) 339-345. doi:10.1007/BF00766072.

[82] S. Tamiyakul, T. Sooknoi, L.L. Lobban, S. Jongpatiwut, Generation of reductive Zn species over Zn/HZSM-5 catalysts for n-pentane aromatization, Appl. Catal. A Gen. 525 (2016) 190-196. doi:10.1016/j.apcata.2016.07.020.

[83] W. Dai, X. Wang, G. Wu, N. Guan, M. Hunger, L. Li, Methanol-to-olefin conversion on silicoaluminophosphate catalysts: Effect of Brønsted acid sites and framework structures, ACS Catal. 1 (2011) 292-299. doi:10.1021/cs200016u.

[84] E.-M. El-Malki, R.A. van Santen, W.M.H. Sachtler, Introduction of Zn, Ga, and Fe into HZSM-5 cavities by sublimation: Identification of acid sites, J. Phys. Chem. B. 103 (1999) 4611-4622. doi:10.1021/jp9901161.

[85] J.A. Biscardi, G.D. Meitzner, E. Iglesia, Structure and density of active Zn species in Zn/H-ZSM-5 propane aromatization catalysts, J. Catal. 179 (1998) 192-202. doi:10.1006/jcat.1998.2177.

[86] S.A. Schmidt, N. Kumar, A. Shchukarev, K. Eränen, J.P. Mikkola, D.Y. Murzin, T. Salmi, Preparation and characterization of neat and $\mathrm{ZnCl} 2$ modified zeolites and alumina for methyl chloride synthesis, Appl. Catal. A Gen. 468 (2013) 120134. doi:10.1016/j.apcata.2013.08.039. 


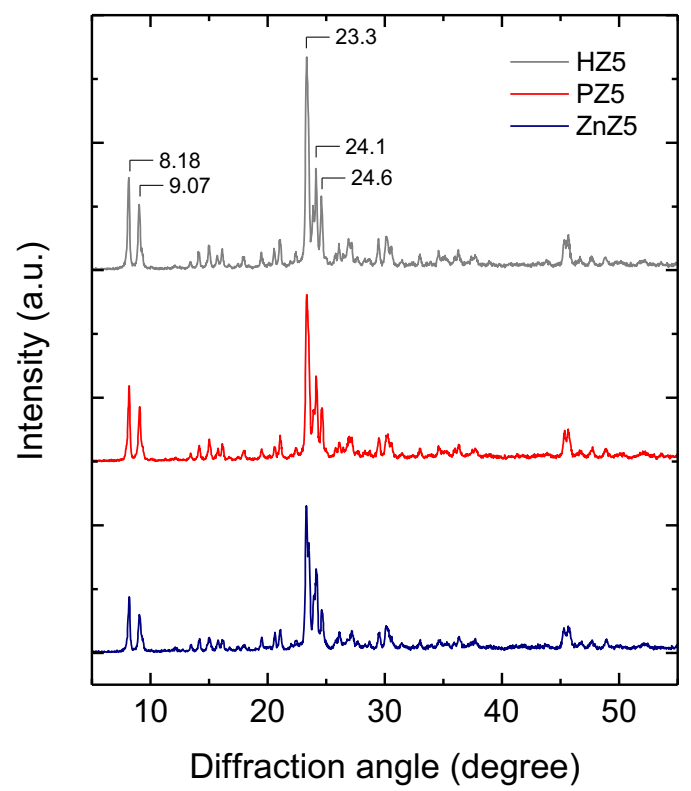

Figure 1. XRD patterns of the parent and modified zeolites. 
(a)

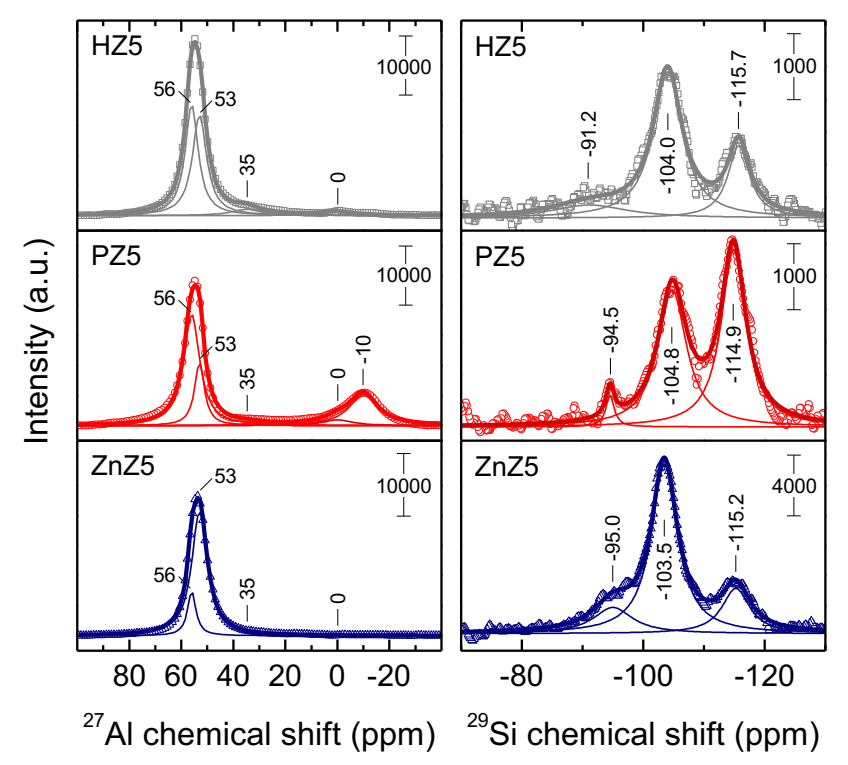

Figure 2. NMR spectra of the parent and modified zeolites: (a) ${ }^{27} \mathrm{Al}$ NMR spectra; (b) ${ }^{29} \mathrm{Si}$ NMR spectra. 
(a)

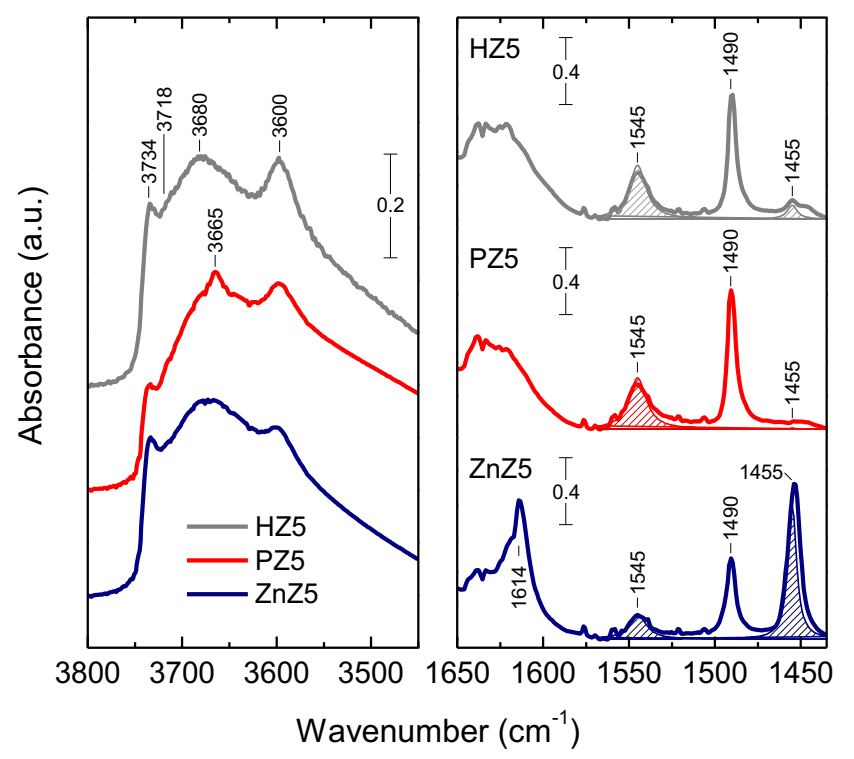

Figure 3. Acid properties of the parent and modified zeolites: (a) FTIR spectra of the zeolites in the 3450-3800 $\mathrm{cm}^{-1}$ region; (b) FTIR spectra of pyridine-saturated zeolites in the $1425-1650 \mathrm{~cm}^{-1}$ region. 
(a)

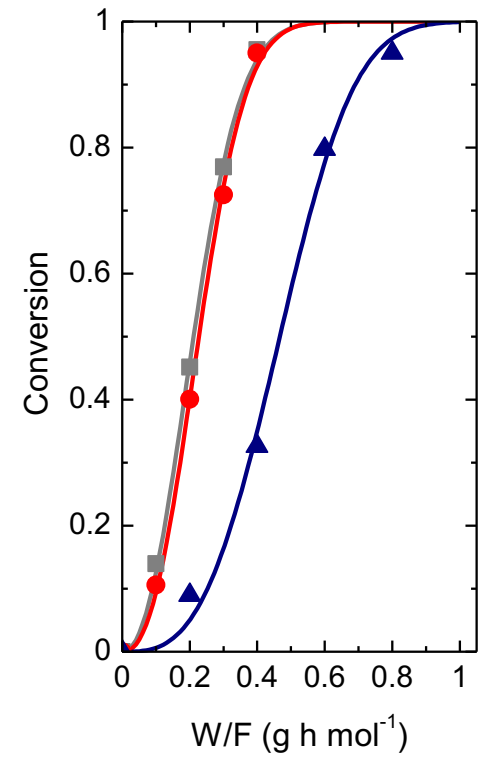

(b)

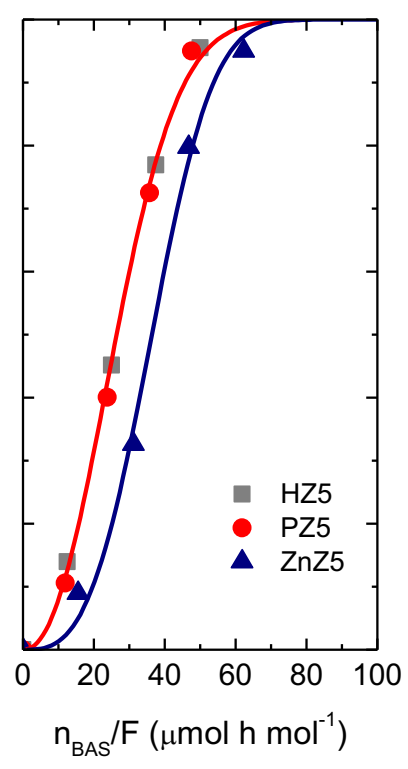

Figure 4. Kinetic behavior at initial conversion for the MTO reaction over the HZ5, PZ5 and ZnZ5 catalysts at: (a) conventional space time values (W/F); (b) apparent space time values $\left(\mathrm{n}_{\mathrm{BAS}} / \mathrm{F}\right)$. Reaction conditions: $400^{\circ} \mathrm{C}$ and $\mathrm{P}_{\mathrm{M}}=1.57$ bar. 


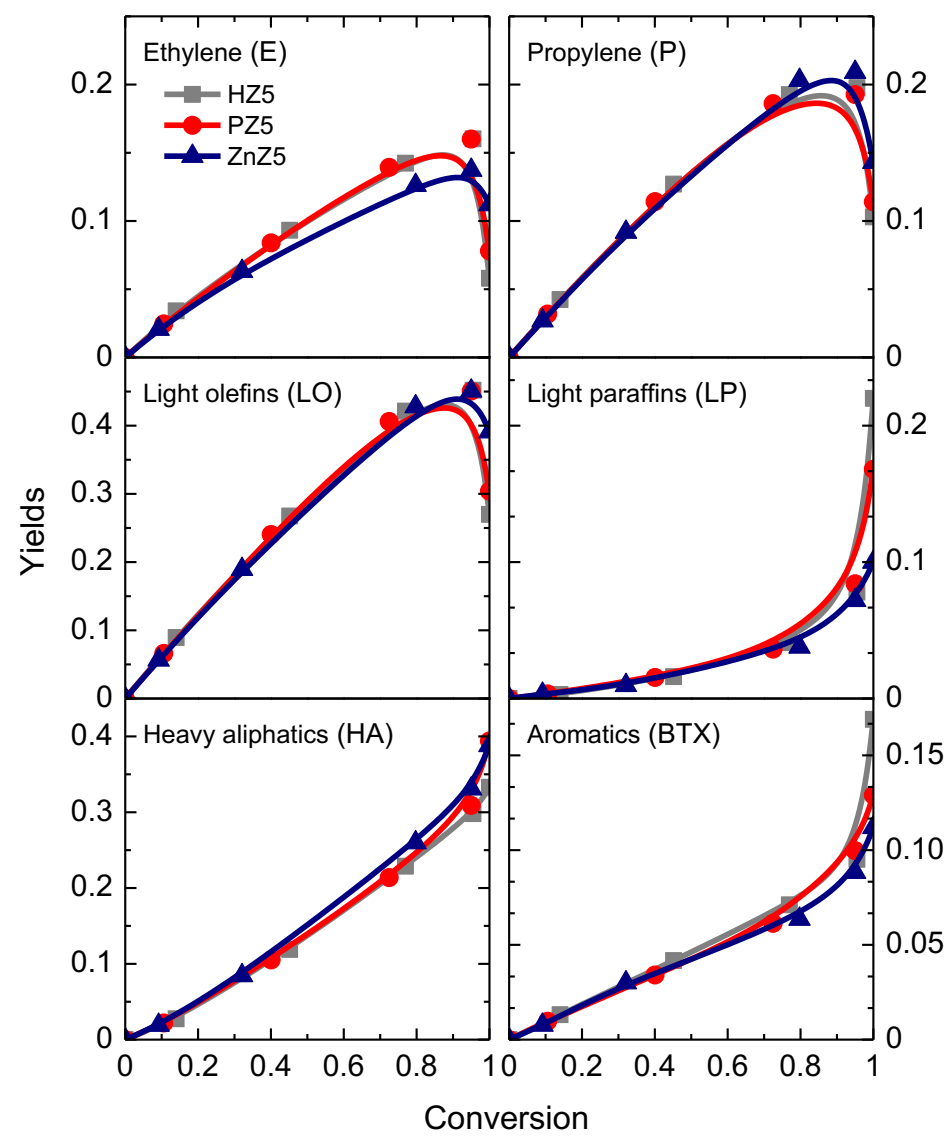

Figure 5. Product distribution for the MTO reaction over the HZ5, PZ5 and ZnZ5 catalysts. Reaction conditions: $400{ }^{\circ} \mathrm{C}$ and $\mathrm{P}_{\mathrm{M}}=1.57$ bar. 
(a)

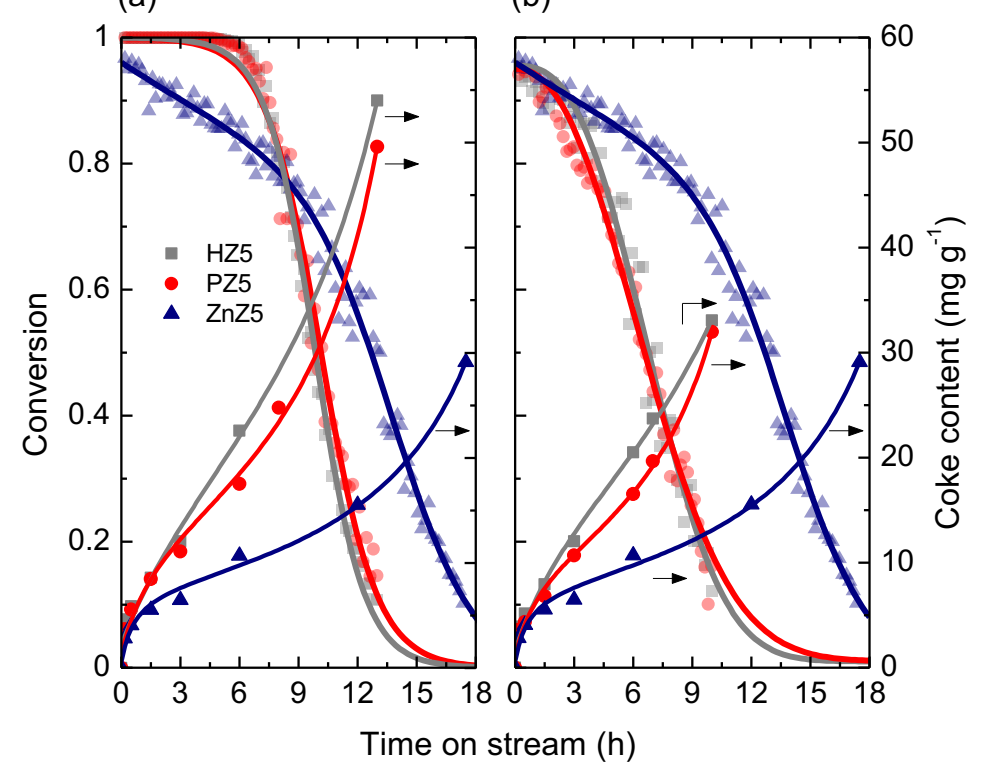

Figure 6. Evolution with TOS of conversion and coke content for the MTO reaction over the HZ5, PZ5 and ZnZ5 catalysts at: (a) identical W/F $=0.8 \mathrm{~g} \mathrm{~h} \mathrm{~mol}^{-1}$; (b) identical initial conversion. Reaction conditions: $400{ }^{\circ} \mathrm{C}$ and $\mathrm{P}_{\mathrm{M}}=1.57$ bar. 
(a)

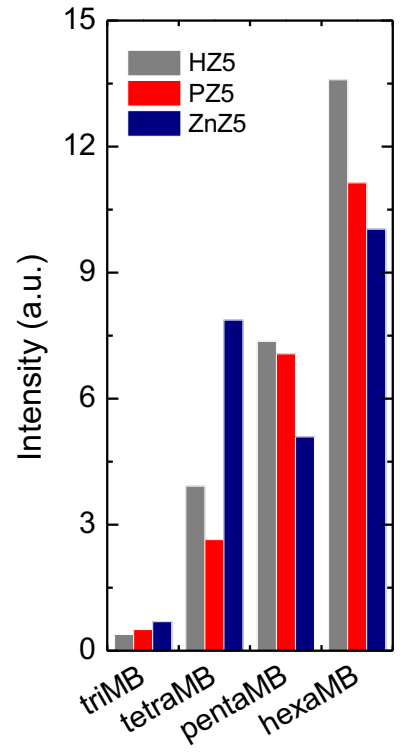

(b)

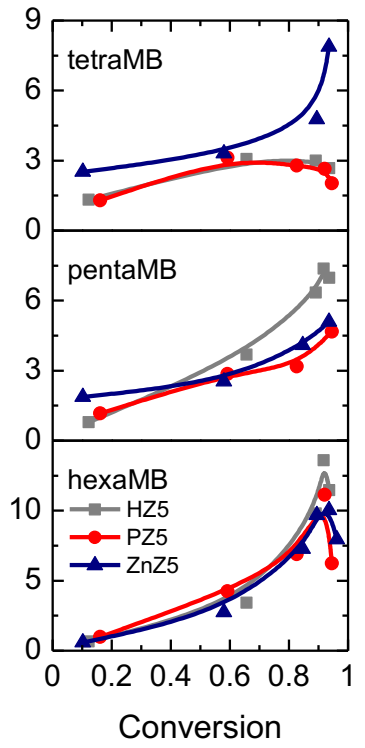

(c)

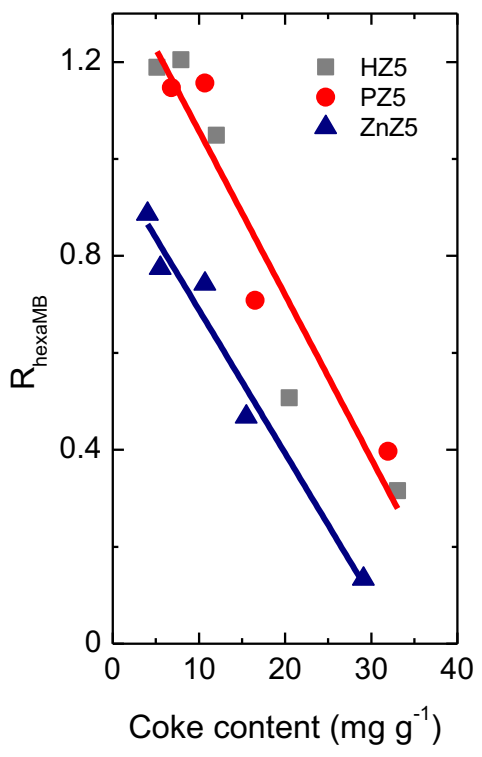

Figure 7. Analysis of retained species in the HZ5, PZ5 and ZnZ5 spent catalysts after the MTO reaction experiments depicted in Figure 5b: (a) distribution of retained species at $\mathrm{TOS}=90 \mathrm{~min}$; (b) evolution of retained species with conversion; (c) correlation between the coke content and $\mathrm{R}_{\text {hexamB }}$. 


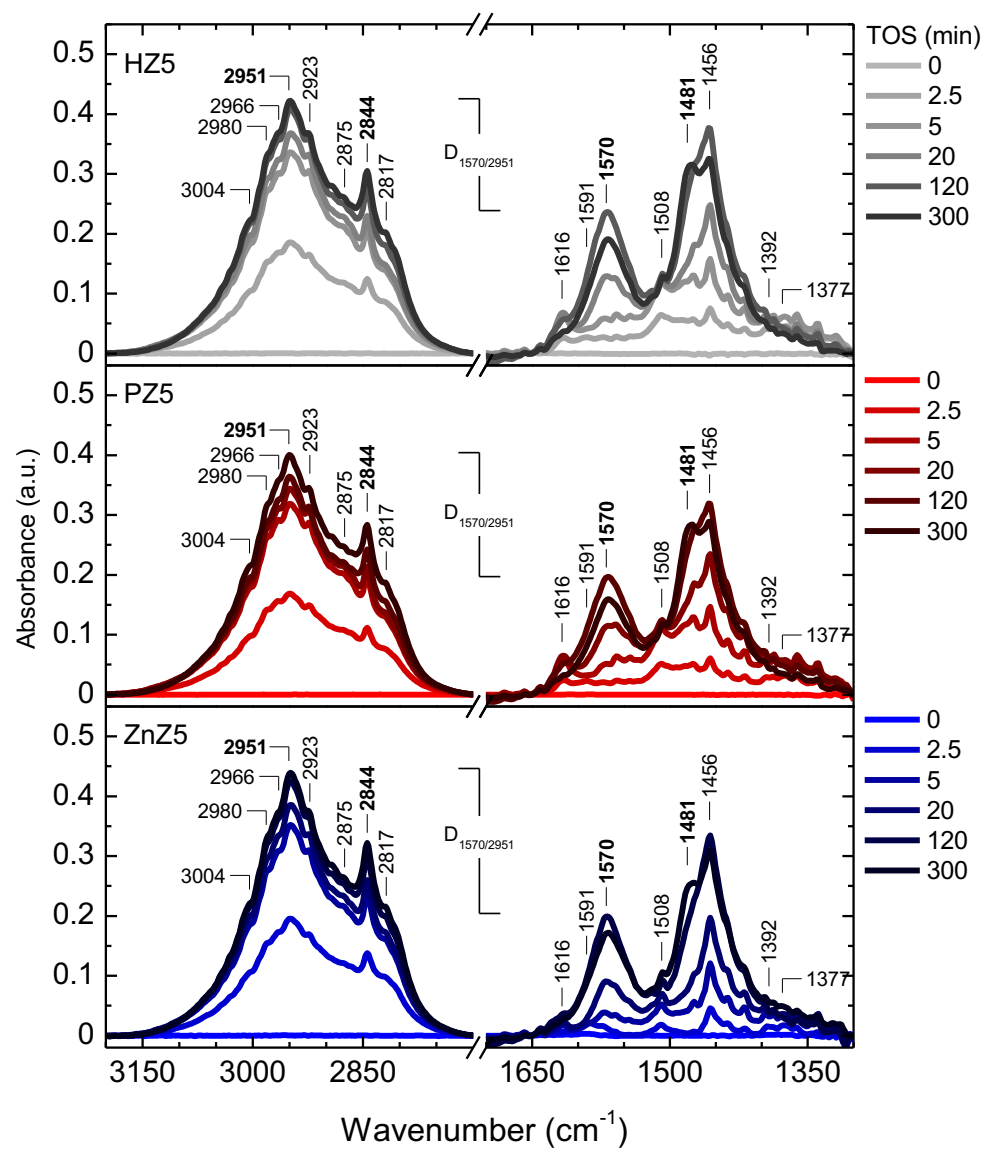

Figure 8. Evolution with TOS of FTIR spectra of the HZ5, PZ5 and ZnZ5 catalysts during the MTO reaction. Reaction conditions: $400{ }^{\circ} \mathrm{C}$ and $\mathrm{P}_{\mathrm{M}}=0.16$ bar. 


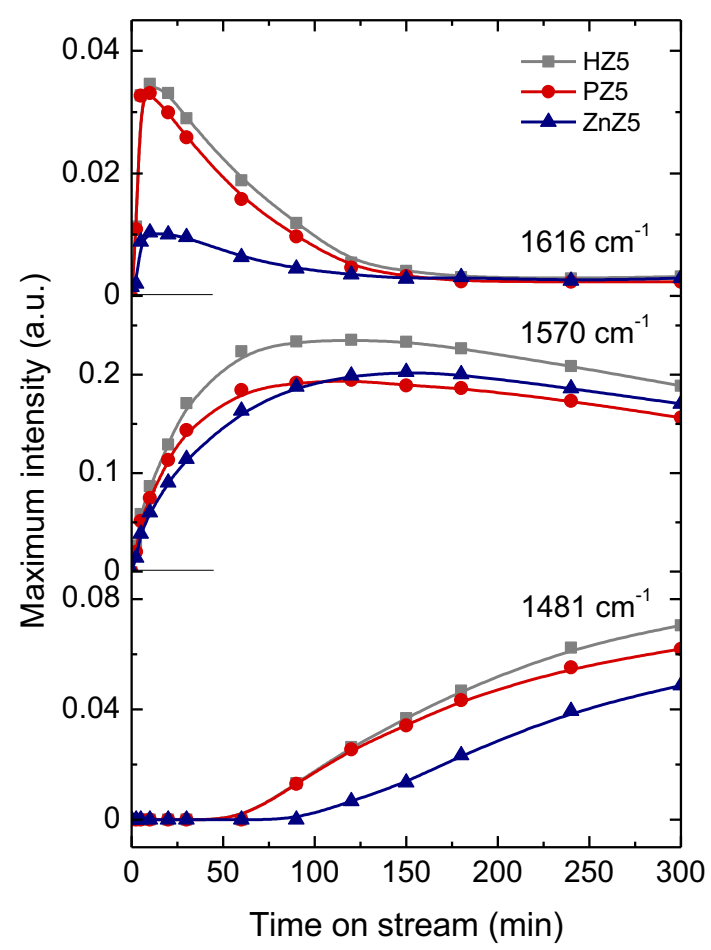

Figure 9. Evolution with TOS of selected FTIR bands for the HZ5, PZ5 and ZnZ5 catalysts during the MTO reaction. Reaction conditions: $400{ }^{\circ} \mathrm{C}$ and $\mathrm{P}_{\mathrm{M}}=0.16$ bar. 


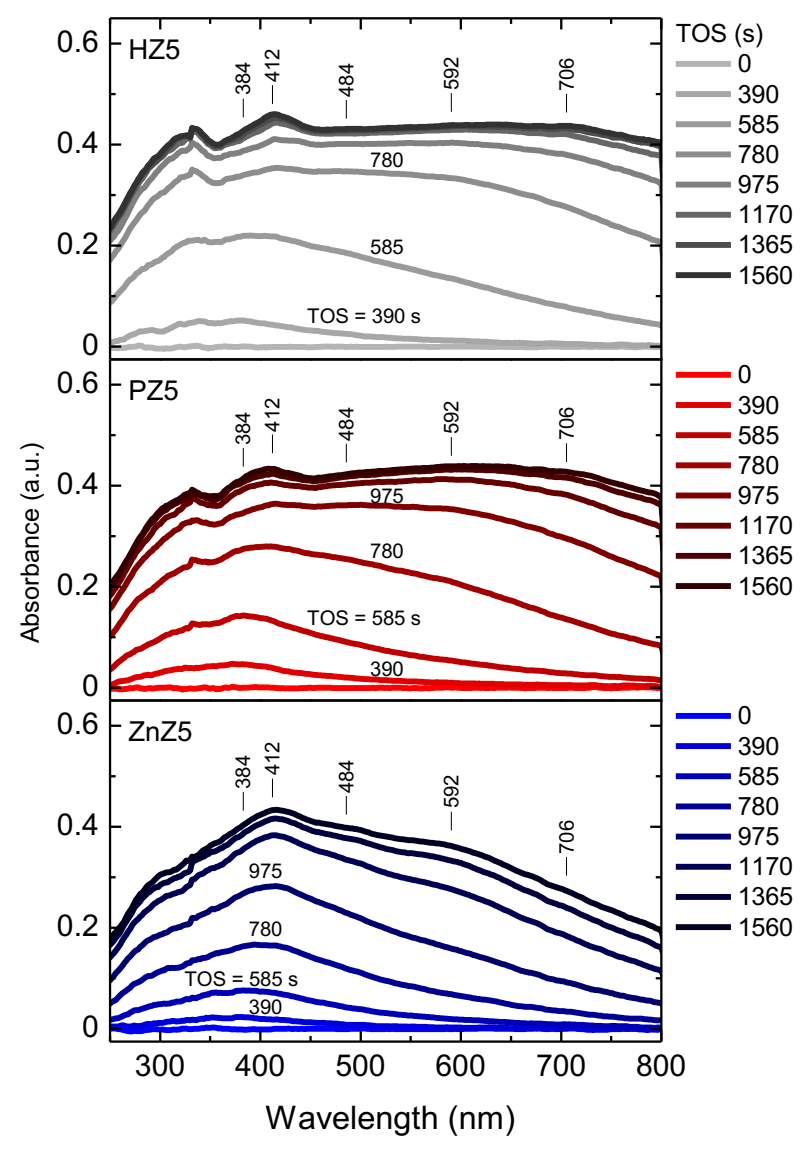

Figure 10. Evolution with TOS of UV-vis spectra of the HZ5, PZ5 and ZnZ5 catalysts during the MTO reaction. Reaction conditions: $400{ }^{\circ} \mathrm{C}$ and $\mathrm{P}_{\mathrm{M}}=0.04$ bar. 


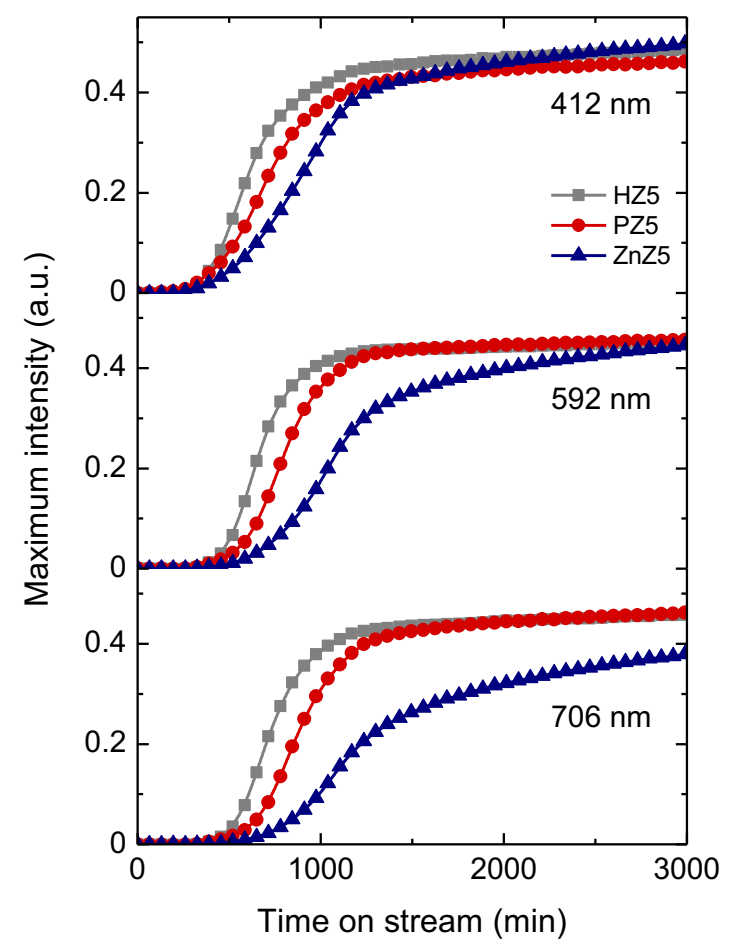

Figure 11. Evolution of selected UV-vis bands with TOS for the HZ5, PZ5 and ZnZ5 catalysts during the MTO reaction. Reaction conditions: $400{ }^{\circ} \mathrm{C}$ and $\mathrm{P}_{\mathrm{M}}=0.04$ bar. 


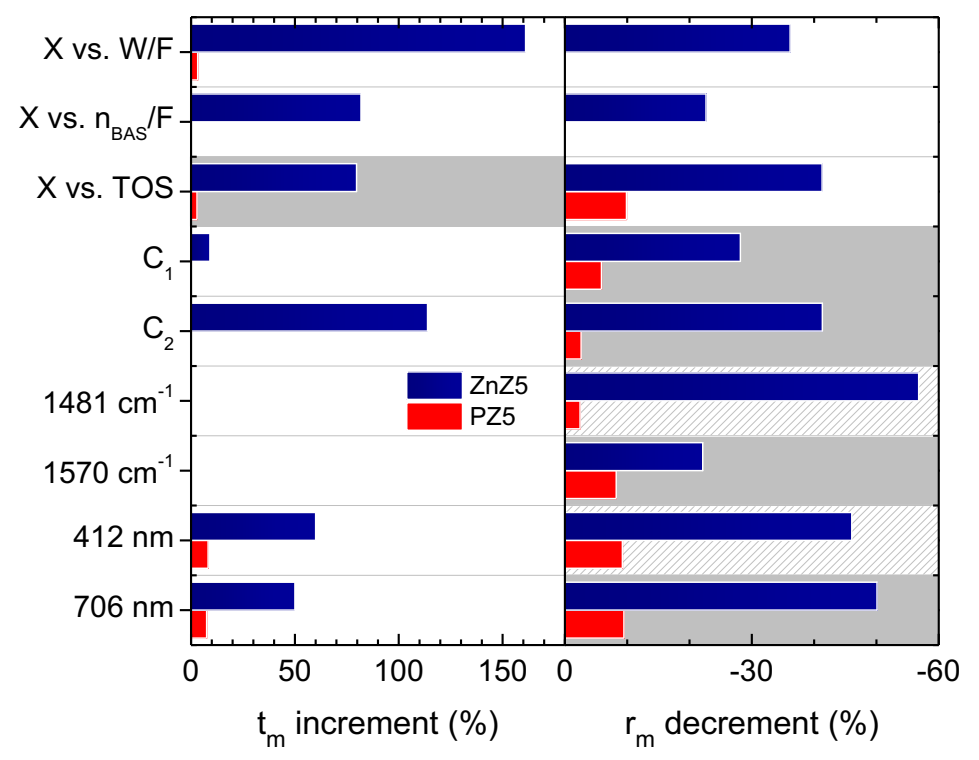

Figure 12. Increment of the $t_{m}$ (associated with induction period) and decrement of $r_{m}$ (associated with the maximum rate of change) of the variables indicated by the evolution of different parameters. 